\title{
DESDOBRAMENTO DA FUNÇÃO QUALIDADE (QFD) APLICADO À PRODUÇÃO DE MUDAS DE CAFÉ (Coffea arabica L. )
}

\author{
Gustavo KazUo Nagumo
}

Dissertação apresentada à Escola Superior de Agricultura "Luiz de Queroz", Universidade de São Paulo, para obtenção do título de Mestre em Agronomia, Área de concentração: Máquinas Agrícolas

PIRACICABA

Estado de São Paulo - Brasil

Agosto - 2005 


\title{
DESDOBRAMENTO DA FUNÇÃO QUALIDADE (QFD) APLICADO À PRODUÇÃO DE MUDAS DE CAFÉ (Coffea arabica L. )
}

\author{
Gustavo Kazuo Nagumo
}

Engenheiro Agrícola

Orientador: Prof. Dr. Marcos Milan

\begin{abstract}
Dissertação apresentada à Escola Superior de Agricultura "Luiz de Queroz", Universidade de São Paulo, para obtenção do título de Mestre em Agronomia, Área de concentração: Máquinas Agrícolas
\end{abstract}

PIRA CICAB A

Estado de São Paulo - Brasil

Agosto - 2005 
Dados Internacionais de Catalogação na Publicação (CIP) DIVISÃO DE BIBLIOTECA E DOCUMENTAÇÃO - ESALQ/USP

Nagumo, Gustavo Kazuo

Desdobramento da função qualidade (QFD) aplicado à produção de mudas de café (Coffea arabica L.) / Gustavo Kazuo Nagumo. - - Piracicaba, 2005.

61 p. : il.

Dissertação (Mestrado) - - Escola Superior de Agricultura Luiz de Queiroz, 2005.

1. Café 2 Cultivo em tubete 3. Desdobramento da função qualidade 4. Enxertia (Fitotecnia) 5. Indicadores de qualidade 6. Mudas 7. Qualidade do produto I. Título

CDD 633.73

"Permitida a cópia total ou parcial deste documento, desde que citada a fonte - O autor" 
Ao meu pai Kazuhiro

À minha mãe Yaeko

Aos meus irmãos Arthur Yoshio e Cesar Hideo,

Pelo apoio durante a vida pessoal e profissional.

À família Shimada, em especial à Marly Satimi pelo apoio e dias ausentes.

E aos meus amigos pelos bons momentos. 


\section{AGRADECIMENTOS}

À Escola Superior de Agricultura "Luiz de Queiroz" (ESALQ/USP) pela excelente estrutura proporcionada durante o período de mestrado.

Ao professor Dr. Marcos Milan pelo apoio e desenvolvimento pessoal que me assegurou os primeiros passos sólidos na carreira profissional.

À Capes pelo apoio, fundamental do início ao término do curso.

À Cooperativa dos Cafeicultores da Região de Marília (Coopemar), principalmente aos agrônomos Caetano e Aurélio pelas instruções, auxílio e por ceder a estrutura da cooperativa para desenvolvimento do trabalho.

Aos professores do Departamento de Engenharia Rural, em especial ao prof. José Paulo Molin pela excelente aprendizagem que foi concedida.

À amizade formada no decorrer do curso, em especial aos amigos: Adriano, Gustavo Fontana, Gustavo Faulin, Raphael, Wladimir e Bettini que iniciaram o curso e aos que marcaram presença: José Vitor, Leonardo, Marcos, Thiago, Pedro.

Aos amigos de faculdade Saulo e Murilo, que auxiliaram principalmente no início do curso.

Aos funcionários do Departamento de Engenharia Rural que auxiliaram nessa caminhada.

À Cia Canavieira de Jacarezinho, em especial José Carlos Turato Filho pela oportunidade de iniciar a carreira profissional.

Aos amigos e colegas da Companhia Melhoramentos do Norte do Paraná (CMNP).

À Marly Satimi Shimada pelo auxílio em todas as etapas do curso.

À minha família que não conteve apoio para término do curso. 


\section{SUMÁRIO}

Página

LISTA DE FIGURAS..................................................................................... vii

LISTA DE QUADROS

RESUMO

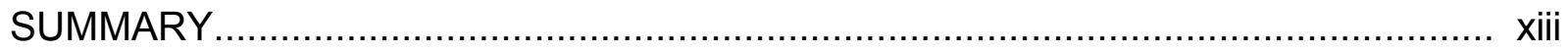

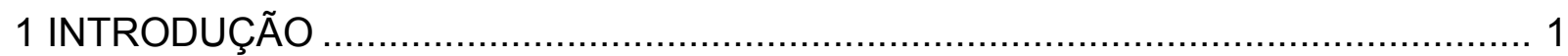

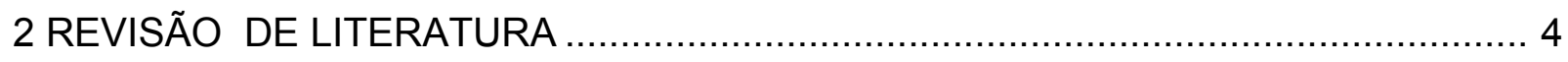

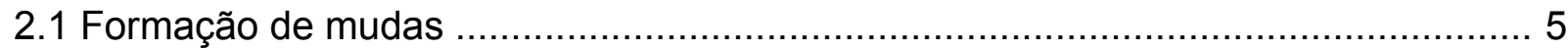

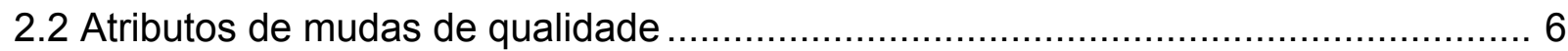

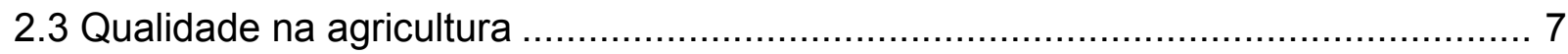

2.4 Desdobramento da Função Qualidade (QFD) ................................................. 9

2.4.1 Origem e expansão do método QFD ............................................................... 9

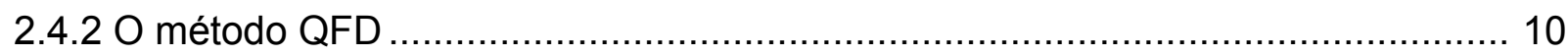

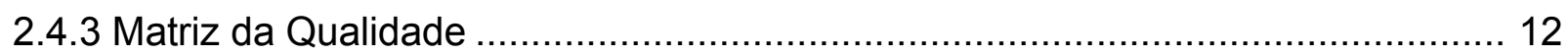

2.4.4 Montagem da Casa da Qualidade ............................................................ 13

2.4.5 Aplicações do método QFD na agropecuária ............................................... 16

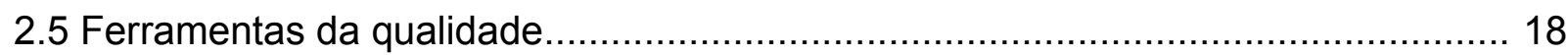

2.5.1 Aplicações das ferramentas da qualidade na agricultura ................................. 19

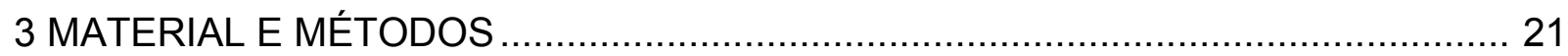

3.1 Aplicação do método QFD na produção de mudas de café ................................... 23

3.2 Construção da Tabela de Desdobramento da Qualidade Exigida........................... 24

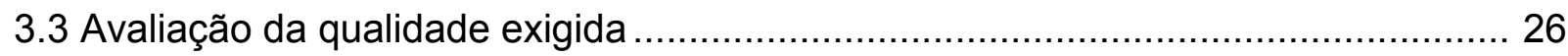

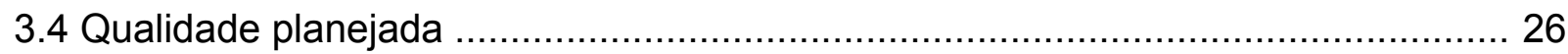

3.5 Extração da qualidade exigida para características da qualidade ......................... 28 
3.6 Correlação entre as características da qualidade e qualidade exigida................. 31

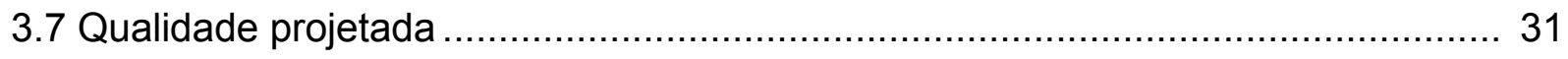

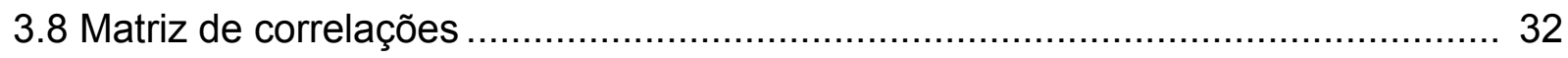

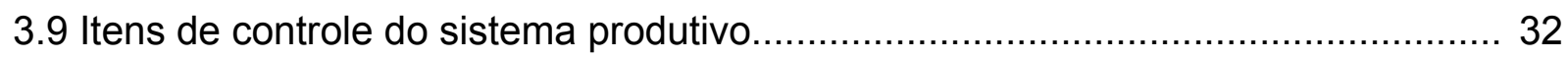

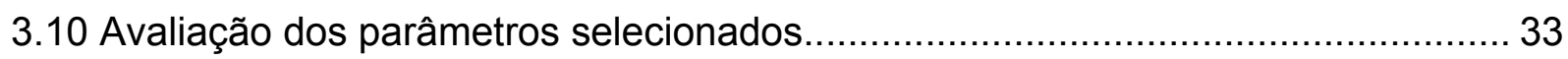

3.10.1 Determinação do estado nutricional.................................................. 33

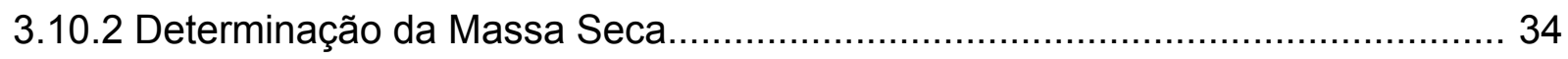

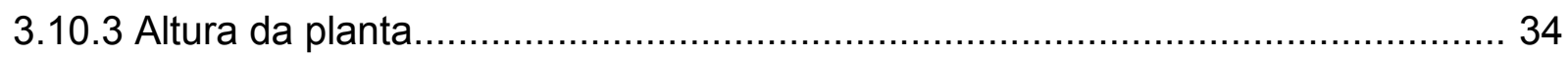

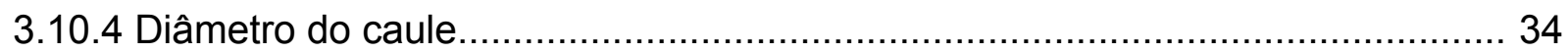

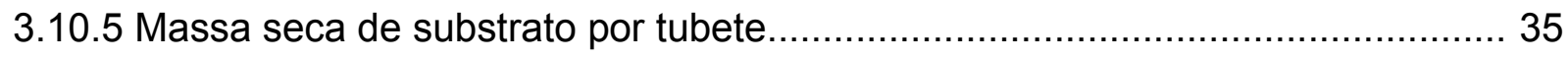

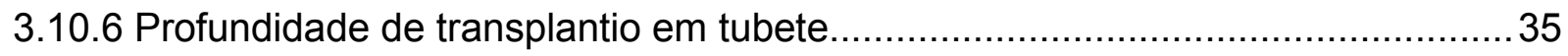

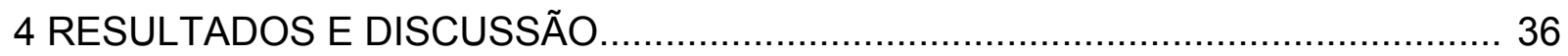

4.1 Qualidade exigida e Grau de importância (Etapa 1)......................................... 36

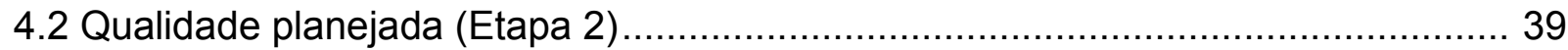

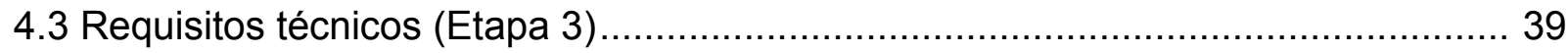

4.4 Relação entre qualidade exigida e requisitos técnicos (Etapa 4) ......................... 39

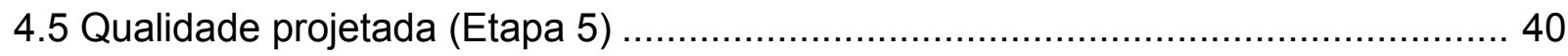

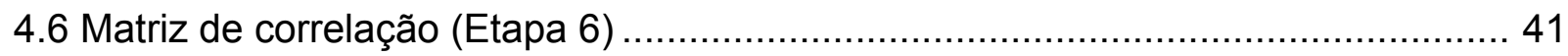

4.7 Avaliação dos indicadores desdobrados ................................................... 41

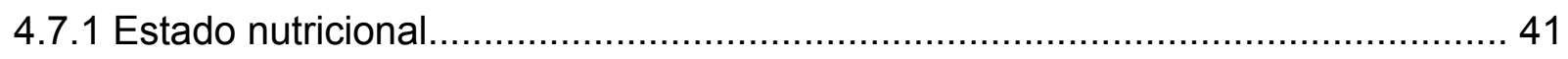

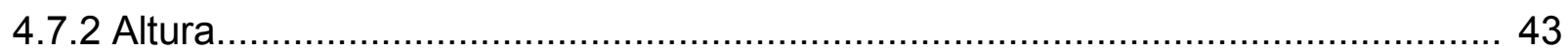

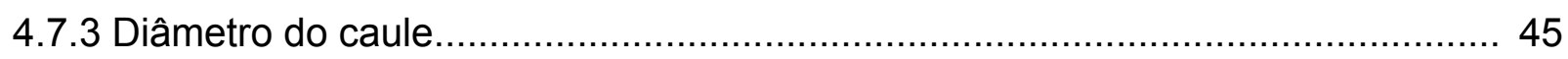

4.8 Diagrama de causa e efeito na produção de mudas de café.................................47

4.8.1 Profundidade de transplantio................................................................ 48

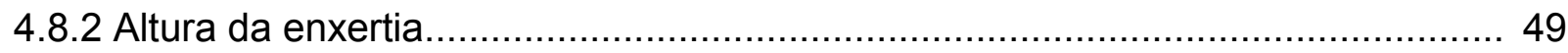

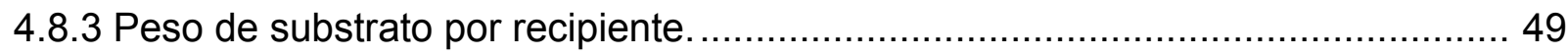

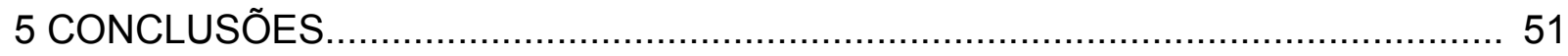

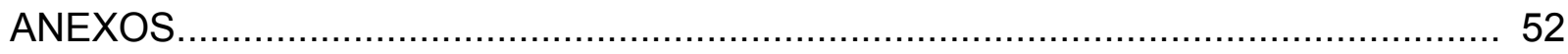

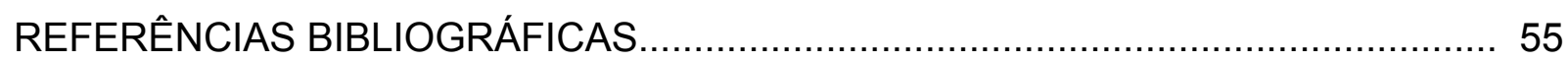




\section{LISTA DE FIGURAS}

Página

1 Casa da Qualidade (adaptado de Mirshawka \& Mirshawka Júnior, 1994). 12

2 Símbolos e valores utilizados para definição do grau de relação das qualidades exigidas e os requisitos técnicos 15

3 Etapa 1, Mudas em estádio inicial (berçário) ................................................. 22

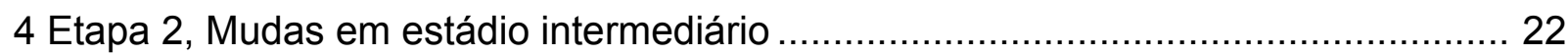

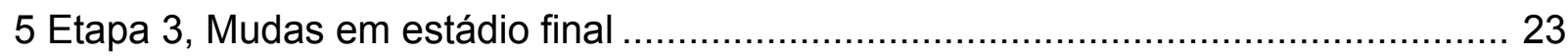

6 Diagrama de Afinidades (adaptado de Dellaretti Filho, 1996) .............................. 25

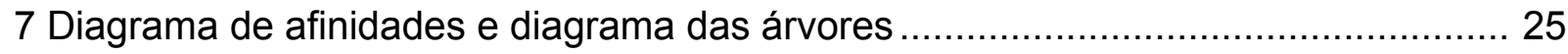

8 Determinação dos Meios Secundários .............................................................. 29

9 Extração da Qualidade Exigida para Características da Qualidade........................ 30

10 Matriz do sistema produtivo de mudas de café (Coffea arábica L.)......................... 38

11 Avaliação do estado nutricional das mudas de café........................................... 42

12 Amplitude do estado nutricional das mudas ....................................................... 43

13 Gráfico de controle para a altura das mudas ................................................... 44

14 Gráfico de controle da amplitude para altura das plantas ................................ 44

15 Histograma da altura das mudas de café ................................................ 45

16 Gráfico de controle da média para diâmetro do caule da planta ......................... 46 
17 Gráfico de controle da amplitude para diâmetro do caule da planta ..................... 46

18 Histograma do diâmetro do caule das plantas ................................................ 47

19 Diagrama de Causa e Efeito na produção de mudas de café ................................ 48

20 Gráfico de controle para profundidade de transplantio (repicagem)..................... 48

21 Gráfico de controle para altura da enxertia ........................................................ 49

22 Gráfico de controle para peso de substrato $(\mathrm{g})$ por tubete. .................................. 50 


\section{LISTA DE QUADROS}

Página

1 Grau de Importância para os itens avaliados ................................................... 26

2 Grau de satisfação dos itens avaliados ............................................................... 27

3 Características nutricionais das mudas de café .................................................. 34

4 Etapas e partes constituintes da matriz da qualidade. .......................................... 36 


\title{
DESDOBRAMENTO DA FUNÇÃO QUALIDADE (QFD) APLICADO À PRODUÇÃO DE MUDAS DE CAFÉ (Coffea arabica L. )
}

\author{
Autor: GUSTAVO KAZUO NAGUMO \\ Orientador: Prof Dr. MARCOS MILAN
}

\section{RESUMO}

A produção de mudas de qualidade constitui um dos principais fatores de sucesso da cultura cafeeira, principalmente para a substituição de cafezais não-produtivos, e implantação de novas técnicas de produção. Através dessa demanda realizou-se um trabalho em conjunto com a Cooperativa dos Cafeicultores da Região de Marília (Coopemar), no município de Marília (SP), estabelecendo e analisando as características exigidas pelos clientes de mudas de café enxertadas, e comercializadas em tubetes plásticos. A aplicação da metodologia foi composta por 2 fases: aquisição das qualidades exigidas pelos clientes com aplicação da metodologia QFD (Casa da Qualidade) e emprego de ferramentas de controle de qualidade no sistema produtivo. A aquisição da qualidade exigida foi composta de entrevistas com os cooperados, clientes de mudas, com a finalidade de captar quais as características e serviços analisados na aquisição da muda de café e qual o grau de importância de cada característica exigida. Nessa etapa os itens de qualidade exigida prazo de entrega, enxerto bem-feito, preço acessível e condições de pagamento 
obtiveram os maiores pesos relativos. Desdobrando as qualidades exigidas mencionadas em requisitos técnicos, o estado nutricional, massa seca da parte aérea, massa seca das raízes, altura da planta e diâmetro do caule foram os itens que alcançaram o maior peso relativo, nesta ordem de importância. No controle produtivo os requisitos técnicos (indicadores de qualidade) selecionados foram submetidos à verificação através da utilização de cartas de controle e histogramas. Com a utilização do diagrama de causa e efeito também pode-se determinar três características importantes: profundidade de plantio, altura de enxertia e peso de substrato por recipiente. Os resultados permitiram avaliar que dentre as características analisadas o estado nutricional, altura e diâmetro do caule apresentaram-se sob controle, porém os itens profundidade de plantio, altura de enxertia e peso de substrato por recipiente evidenciaram que o processo ocorria fora de controle. Devido à baixa correlação com as características da qualidade, os itens de qualidade exigida alcançaram baixo peso relativo nos respectivos itens de qualidade projetada $\mathrm{e}$ os processos fora de controle ocorridos durante o processo produtivo surgiram como proposta para melhorias para obtenção da muda de café com atributos da planta e dos serviços intrínsecos, segundo exigência dos clientes. 


\section{QFD METHODOLOGY APPLIED TO THE PRODUCTION OF SEEDLING OF COFFEE (coffea arabica L. )}

Author: GUSTAVO KAZUO NAGUMO

Adviser: Prof. Dr. MARCOS MILAN

\section{SUMMARY}

The production of quality seedling constitutes one of the main factors of success of the coffee cultivation, mainly for the substitution of not-productive coffee crops, and implantation of new techniques of production. A collaborative work with Cooperative of the Coffee Producers of the Marília Region (Cooperativa dos Cafeicultores da Região de Marília - Coopemar) was carried out to establish and analyze the characteristics required by the customers of seedling of grafted coffee which are commercialized in plastic tubes. This work consists of two phases: i) Quality control required by the customers applying the QFD methodology (House of Quality); and, ii) The utilization of quality control tools in the production system. Interviews with customers of seedling were carried out with the purpose to discover which characteristics and services analyzed in the acquisition of the coffee seedling and how important each required characteristic was. In the first phase, the quality requirements, such as the delivery deadline, high quality grafting, affordable prices and the conditions 
of payment presented major weight in the analysis. The characteristics such as the nutrition level, dry mass of the aerial part, dry mass of the root, the height and diameter of stalk for the seedling were met satisfactorily, in this order of importance. In the productive control (indicators of quality) technical requirement selected had been submitted to the verification through the use of letters of control and histograms. With the use of the diagram of cause and effect it can also determine three important characteristics: depth of seedling, height of grafting and weight of the property per container. The results had conclued that amongst the analyzed characteristics such as the nutrition level, the height and diameter of stalk for the seedling were met satisfactorily. Nevertheless, other requirements like the depth of seedling, height of grafting and weight of the property per container did not meet the criteria. Due to low correlation with the characteristics of the quality, itens of demanded quality had reached low relative weight in respective itens of projected quality and the occurred processes out of control during the productive process had appeared as proposal for improvements for attainment of the seedling of coffee with attributes of the plant and the intrinsic services, according to requirement of the customers. 


\section{INTRODUÇÃo}

$\mathrm{Na}$ cultura cafeeira, o Brasil se destaca mundialmente como maior produtor, com 29 milhões de sacas, correspondentes à área de 2,2 milhões de hectares na safra 2003/2004 (IBGE, 2004). O país também mantém a posição de maior exportador mundial de café verde, com 22,8 milhões de sacas anuais e faturamento de US\$1,3 bilhão no ano de 2003 (Silva, 2004).

O consumo mundial de café corresponde a 110 milhões de sacas anuais, sendo o Brasil o segundo maior consumidor com 14 milhões. O país apresenta também um significativo aumento na taxa média de consumo, de $2,6 \%$ ao ano, dobro do crescimento médio mundial (1,5\%) (ABIC, 2004). Apesar do acréscimo no consumo mundial do produto, o preço da saca tem decaído consideravelmente ao longo dos anos em virtude da concorrência com os demais países produtores.

A conseqüência da diminuição da margem de lucro obrigou a reestruturação do setor nas últimas décadas, visando a melhoria da produtividade e redução nos custos de produção. Estimativas apresentam um parque cafeeiro de 5,5 bilhões de covas, relativos a 4,8 bilhões em franca produção e cerca de 622 mil (205 mil hectares) compreendendo cafezais novos, ou em formação (CONAB, 2004). Avalia-se também que $10 \%$ sejam de cafeeiros com mais de 20 anos de idade e que provavelmente deverão ser substituídos nos próximos anos. Considerando esse aspecto e a utilização de novas áreas para a implantação da lavoura cafeeira nas diferentes regiões do país, a produção de mudas de qualidade constitui um dos principais fatores de sucesso da cultura. 
A grande vantagem da adoção do sistema de mudas é o estabelecimento da cultura com espaçamento, população predeterminada, plantas de tamanho uniforme, menor incidência de problemas fitossanitários e menor competição inicial com plantas daninhas. Isso permite um melhor estande da cultura, além de condicionar ao cafeeiro uma carga genética que influi decisivamente na formação da estrutura do sistema radicular e da parte aérea da planta, resultando na melhoria da produtividade (Minami, 1995).

Em condições naturais de solo e clima, a utilização de mudas produzidas em recipientes individuais também possibilita maior taxa de sobrevivência e maior crescimento individual das plantas. Melo (1999) relata que a forma usual da produção de mudas de cafeeiro tem sido através da utilização de sacos plásticos e de substrato composto por terra de subsolo e esterco animal, complementado com fertilizantes químicos. Porém recentemente, tem-se utilizado também recipientes de menor volume: os tubetes plásticos. Essa alternativa apresenta algumas vantagens quando comparado ao sistema tradicional de formação de mudas: facilidade no manuseio e transporte, redução da área necessária para o viveiro e menor volume de substrato.

Um dos pontos mais importantes então, para a produção de mudas de café, refere-se à obtenção das suas características técnicas. O método QFD (Desdobramento da Função Qualidade), desenvolvido no Japão na década de 60 e consagrado no meio industrial, principalmente na industria automobilística, define as exigências dos clientes como meio para determinação das características quantitativas no meio produtivo. Ele traduz as necessidades dos clientes em especificações técnicas de produtos e processos, assegurando que essas especificações possam ser cumpridas pelas áreas operacionais.

Considerando-se a importância da cultura cafeeira na economia do país e a necessidade de obter-se as especificações para a produção de mudas de qualidade para atender a expansão da cultura em novas áreas, o objetivo 
desse trabalho é de estabelecer e analisar as características fundamentais na produção de muda de café. 


\section{REVISÃO DE LITERATURA}

Sendo o café uma cultura perene, explorada continuamente por longos períodos e em razão da ampliação de áreas de plantio e necessidade de substituição de lavouras não-produtivas o plantio de mudas de qualidade é essencial para condicionar ao cafeeiro as características desejadas para formação da estrutura da planta (Matiello, 1991).

Segundo Matiello \& Barros (1991) a formação de mudas de café de qualidade constitui um fator importante e até mesmo limitante para a produtividade cafeeira, determinando, segundo Campos (2002), um fator estratégico para tornar a lavoura cafeeira mais competitiva, através de mudas bem formadas e com porte adequado, influenciando decisivamente no desenvolvimento da cultura, e conseqüentemente em sua produtividade.

$\mathrm{Na}$ área florestal o êxito na formação de florestas de alta produção, depende, em grande parte, da qualidade das mudas plantadas, que além de terem que resistir às condições adversas encontradas no campo após o plantio deverão sobreviver e, por fim, produzir árvores com crescimento volumétrico economicamente desejável (Gomes et al., 1991).

Os custos de produção de cada muda são mais elevados com a utilização de técnicas modernas, porém a produtividade deve aumentar e os riscos da cultura devem diminuir consideravelmente através de plantas de melhor qualidade, segundo Minami (1995).

A demanda por mudas de café é contínua em razão da ampliação da área de plantio e necessidade de substituição de lavouras antigas e a implantação de modernas técnicas de produção, com o aumento da densidade 
de plantio, novas cultivares que permitem maior produtividade, maior resistência a doenças e excelente qualidade de bebida justificando a substituição de antigos parques cafeeiros (Tavares Júnior, 2004).

\subsection{Formação de mudas}

Há muito tempo, a forma usual da produção de mudas de cafeeiro tem sido através da utilização de sacos plásticos e de substrato composto por terra de subsolo e esterco animal, complementado com fertilizantes químicos. Porém recentemente, têm-se utilizado também recipientes de menor volume: os tubetes plásticos, utilizando substratos comerciais. Segundo Thomaziello et al. (2000) as grandes virtudes são a economia de espaço e de transporte, sua qualidade e sua segurança, no que diz respeito à introdução de nematóides parasitos do café nas áreas de plantio. Outro grande fator positivo é a possibilidade de se produzir em grande escala mudas de café enxertadas.

Nessa tendência mundial pela busca incessante de alta produtividade com qualidade, Guimarães (1998) afirma que a introdução de novas tecnologias vem consolidando o sistema de formação de mudas em "contêiners" ou tubetes para mudas de café, com grande vantagem pelo alto grau de tecnologia aplicado.

Visando verificar os parâmetros morfológicos na avaliação da qualidade de mudas de Eucalyptus grandis, Gomes et al. (2002) utilizou quatro tamanhos diferentes de tubetes de plástico rígido, com volumes de 50, 110 , 200 e $280 \mathrm{~cm}^{3}$, concluindo que os tubetes de $110 \mathrm{~cm}^{3}$ devem ser considerados para mudas com 90 dias de idade e após essa idade os volumes dos recipientes começam a restringir o crescimento das mudas.

Analisando o potencial de regeneração de raízes (PRR) de Eucalyptus camaldulensis e urophylla, Barroso et al. (2000) utilizaram tubetes e blocos prensados aliados a diferentes tipos de substratos: composto orgânico de bagaço de cana-de-açúcar + torta de filtro + uréia; casca decomposta de 
eucalipto + vermiculita. Verificando os parâmetros morfológicos e avaliação no campo concluiu-se que a casca de eucalipto decomposta + vermiculita aliado à utilização de tubetes apresentaram os maiores índices de PRR para as mudas de Eucalyptus camaldulensis.

\subsection{Atributos de mudas de qualidade}

Segundo Carneiro (1995) os padrões das mudas são expressos por números ou indicadores de qualidade que exprimem a capacidade de sobrevivência e desenvolvimento da planta. A caracterização da qualidade e acompanhamento das mudas desde a semeadura até seu desenvolvimento gera informações sobre as quais as práticas de classificação podem ser baseadas.

Minami (1995) cita como principais atributos de uma muda a alta qualidade e a constituição genética; devendo ser bem formada, com todas as características desejáveis e em condições de dar continuidade ao desenvolvimento, quando colocada em local definitivo; sadia, sem vestígios de doenças, pragas ou danos físicos; não devendo apresentar estruturas de propagação de plantas daninhas; ser de custo compatível com a necessidade do produtor e deve ser de fácil transporte e manuseio.

Classificando os parâmetros morfológicos que determinam a qualidade de mudas florestais, Schmidt-Vogt (1966), citado por Carneiro (1995) afirmou que a altura da parte aérea, atributos de vigor (peso total da muda, peso da parte aérea, diâmetro do colo), capacidade de enraizamento (peso das raízes e comprimento das raízes), capacidade de assimilação (ramificação, formação de folhas ou acículas, qualidade e quantidade de brotos) e outros parâmetros (comprimento de acículas, comprimento de raízes).

Gomes et al. (2002) avaliando parâmetros morfológicos de mudas de Eucalyptus grandis, concluiram que a adoção da altura e a relação altura/peso 
da parte aérea devem ser consideradas, pelo fato de serem parâmetros que apresentaram boa contribuição relativa ao padrão de qualidade das mudas. Os autores afirmaram que a adoção da altura para estimar a qualidade das mudas poderá ser utilizada, uma vez que ela foi um dos parâmetros que apresenta boa contribuição relativa, além de sua medição ser fácil e não-destrutiva.

Para mudas de café, Melo (1999) destacou que as características desejadas na muda de café podem ser obtidas através da inferência dos seguintes parâmetros: número de pares de folhas verdadeiras; diâmetro do caule; altura da planta; área foliar e peso da matéria-seca do sistema radicular e da parte aérea.

Para avaliação da influência das características das sementes de café da espécie arábica em relação ao seu potencial fisiológico e a qualidade da muda formada, Favarin et al. (2003) utilizaram as variáveis germinação e índice de velocidade de emergência das mudas (qualidade da semente) e através da área foliar total e das folhas cotiledonares, altura das plantas, diâmetro do caule e matéria seca das folhas, caule e raízes avaliaram a qualidade da muda de café.

Barbizan et al. (2002) verificaram os efeitos de diferentes formas de aplicação de fertilizantes sobre o desenvolvimento de mudas de cafeeiros (Coffea arabica L., cv. Mundo Novo) produzidas em tubetes plásticos. As características avaliadas foram: altura de plantas, diâmetro de caule, número de pares de folhas, matéria seca de raízes e parte aérea, volume de raízes e área foliar, concluindo que a fertirrigação pode ser utilizada como complemento de adubação inicial no substrato e o fertilizante de liberação lenta teve efeito positivo sobre o desenvolvimento das mudas.

\subsection{Qualidade na agricultura}

O Brasil é ainda um país desprovido de experiências e conhecimentos sobre Controle de Qualidade aplicado à área agropecuária, entretanto técnicas 
de qualidade amplamente aplicadas no setor industrial podem ser adaptados ao setor de forma a garantir a melhoria no processo produtivo da empresa (Trindade, 1993).

Tradicionalmente o conceito de qualidade na agricultura associa a certas manifestações físicas mensuráveis ou características detectáveis sensorialmente, capazes de atestar algum efeito benéfico ou positivo ao produto. O conceito moderno envolve um conjunto integrado pelo produto e seu contexto, incluindo todo o sistema produtivo correspondente num sentido amplo e não apenas algumas manifestações isoladas (Bonilla, 1994).

A qualidade, produtividade e competitividade, segundo Bonilla (1993) são valores que afetam profundamente a agricultura atual, sendo fundamentais para permanência no mercado. Isso implica em cumprir exigências fitossanitárias, limites de tolerância de resíduos tóxicos, padrões de compradores referentes à cor, nível de defeitos, grau de maturação, sabor, tamanho, além das características da embalagem. Os gastos em Qualidade Total (qualidade de processos e qualidade do produto) geram economia em matérias-primas (insumos), em tempo de produção, em retrabalho e em perdas do produto, como resultante, podem-se ainda praticar preços mais competitivos.

Trindade (1993) desenvolveu um sistema de qualidade mais participativo, em que o pessoal de operação das empresas florestais pudessem se envolver com os aspectos da qualidade, buscando-se aplicar e adaptar algumas técnicas de controle de qualidade utilizados na atividade industrial, concluindo-se que a gestão participativa da qualidade é um caminho inteligente e racional para que as empresas possam atingir seus objetivos, aumentando a qualidade de seus produtos, reduzindo os custos e melhorando o nível de participação de seus funcionários. 


\subsection{Desdobramento da Função Qualidade (QFD)}

O desdobramento da função qualidade é um método que traduz as necessidades e desejos dos clientes em especificações técnicas de produtos e processos, assegurando que estas especificações possam ser cumpridas pelas áreas operacionais (Akao, 1996). Stahl (1995) afirma que o projeto de produtos e serviços é o primeiro passo para assegurar qualidade e a confiabilidade de clientes.

O QFD é um método que se destaca quanto à forma de obter as exigências dos clientes e determinar qual a melhor maneira de atender aos seus desejos com os recursos disponíveis, considerando as especificações para o produto ou serviço de forma ampla, ou os problemas específicos, e através de uma série de matrizes, decompõem os mesmos em específicas atribuições de ação. Essas atribuições estabelecem o nível mínimo de esforço que precisa ser feito para que se satisfaça o cliente (Mirshawka \& Mirshawka Júnior, 1994).

\subsubsection{Origem e expansão do método QFD}

Cheng et al. (1995) relatam que o QFD foi criado no Japão, pelos professores Shiguero Mizuno e Yoji Akao e aperfeiçoado pelo grupo do professor Akao, hoje com base na Universidade de Tamagawa. Guinta \& Praizler (1993) afirmam que esse método permitiu às empresas japonesas vincular cada etapa do processo de construção à satisfação de determinada exigência do cliente.

A primeira aplicação sistematizada do método QFD foi realizada na Kobe Shipyards of Mitshubishi Heavy Industries (Estaleiros da Mitsubishi em Kobe) em 1972, através da divulgação da Matriz da Qualidade (Casa da Qualidade), base do método QFD (Akao, 1996). 
Segundo Miguel et al. (2003) o QFD surgiu a partir das necessidades de garantir a qualidade no desenvolvimento do produto, ou seja, na fase de projeto, de forma a garantir esse projeto na pré-produção, isto é, antes do produto entrar em fabricação.

A partir de 1983 com a publicação do artigo sobre a aplicação de QFD nas indústrias japonesas, na revista Quality Progress o método se tornou difundido, sendo aplicado sistematicamente nos anos posteriores em algumas das principais empresas dos países europeus e Estados Unidos (Akao, 1997). Em 1989 o QFD é apresentado no Brasil, no Congresso Internacional de Controle de Qualidade.

\subsubsection{O método QFD}

Segundo Campos (1992) o controle de qualidade aborda 3 objetivos fundamentais dentre eles o planejamento da qualidade desejada pelos clientes, que implica em saber suas necessidades, traduzir essas necessidades em características mensuráveis para o processo produtivo.

QFD é uma ferramenta de planejamento da qualidade poderosa dentro do programa de TQC, baseado nas necessidades do cliente. Estas exigências são então detalhadas, transformadas em requisitos do processo $\mathrm{e}$ finalmente em especificações operacionais, mostrando e documentando as informações na forma de matrizes (Hakes, 1991; Miguel et al, 2003; Mirshawka \& Mirshawka Junior, 1994).

Dentre os benefícios gerados, destacam-se a importância do papel do QFD como um método para sistematizar o processo de desenvolvimento, bem como outros benefícios para a equipe, tais como melhoria nas habilidades de planejamento, disseminação do conhecimento e melhoria de comunicação entre as áreas funcionais (Miguel et al, 2003).

Segundo Cheng et al. (1995) os benefícios do QFD, já comprovados pela sua aplicação, são: redução do tempo de desenvolvimento; redução do 
número de mudanças de projeto; redução das reclamações de clientes; redução de custos/perdas; redução de transtornos e mal estar entre funcionários; aumento de comunicação entre departamentos funcionais; crescimento e desenvolvimento de pessoas através do aprendizado mútuo.

Bonilla (1993) cita que a necessidade de romper barreiras entre os diversos setores de uma empresa é de fundamental importância para criação de equipes de trabalho, incluindo pessoal de todas as áreas vinculadas ao processo produtivo: materiais, projeto de produto, projeto de processos, produção, vendas, assistência técnica.

Segundo Miguel \& Weidmann (1999) o processo de aplicação da ferramenta QFD no ciclo de desenvolvimento de produtos envolvem as seguintes etapas: definição e aplicação do QFD; definição da equipe multifuncional; obtenção das informações do cliente; construção da "Casa da Qualidade"; Desdobramento da Função Qualidade.

Carnevalli et al (2003) avaliaram a utilização do método QFD no Brasil, principalmente pelas maiores empresas privadas por faturamento. A pesquisa indicou que a maioria das empresas iniciaram a aplicação do método na década de 90 , evidenciando que a utilização do método é recente no país. $\mathrm{O}$ aumento da satisfação dos clientes e a melhoria do trabalho em equipe devido à melhoria na comunicação entre as áreas funcionais foram os principais benefícios. Em relação às dificuldades para implementação do QFD o principal foi relacionado a falta de experiência da ferramenta em sua utilização.

A satisfação dos clientes aumenta a medida que o produto ou serviço passa a atender sucessivos níveis de requisitos. No nível mínimo estão os itens de qualidade obrigatória ou compulsória, passando pela qualidade linear e atrativa, sendo esta última a menos tangível e mais difíceis de atender (Guinta \& Praizler, 1993). 


\subsubsection{Matriz da Qualidade}

Segundo Akao (1996) a Matriz da Qualidade é uma sistematização das qualidades verdadeiras (exigida pelos clientes), considerando principalmente as funções, e expressa a relação existente entre essas funções e as características da qualidade (Figura 1).

O QFD também atribui pesos às demandas do cliente e uma classificação das características funcionais do produto em relação às dos produtos dos concorrentes. O objetivo do QFD é identificar características do produto que precisam ser melhoradas. O processo QFD é repetido até a satisfação do cliente com o projeto dos produtos não conseguir mais identificar características que possam ser melhoradas (Gaither \& Frazier, 2001).

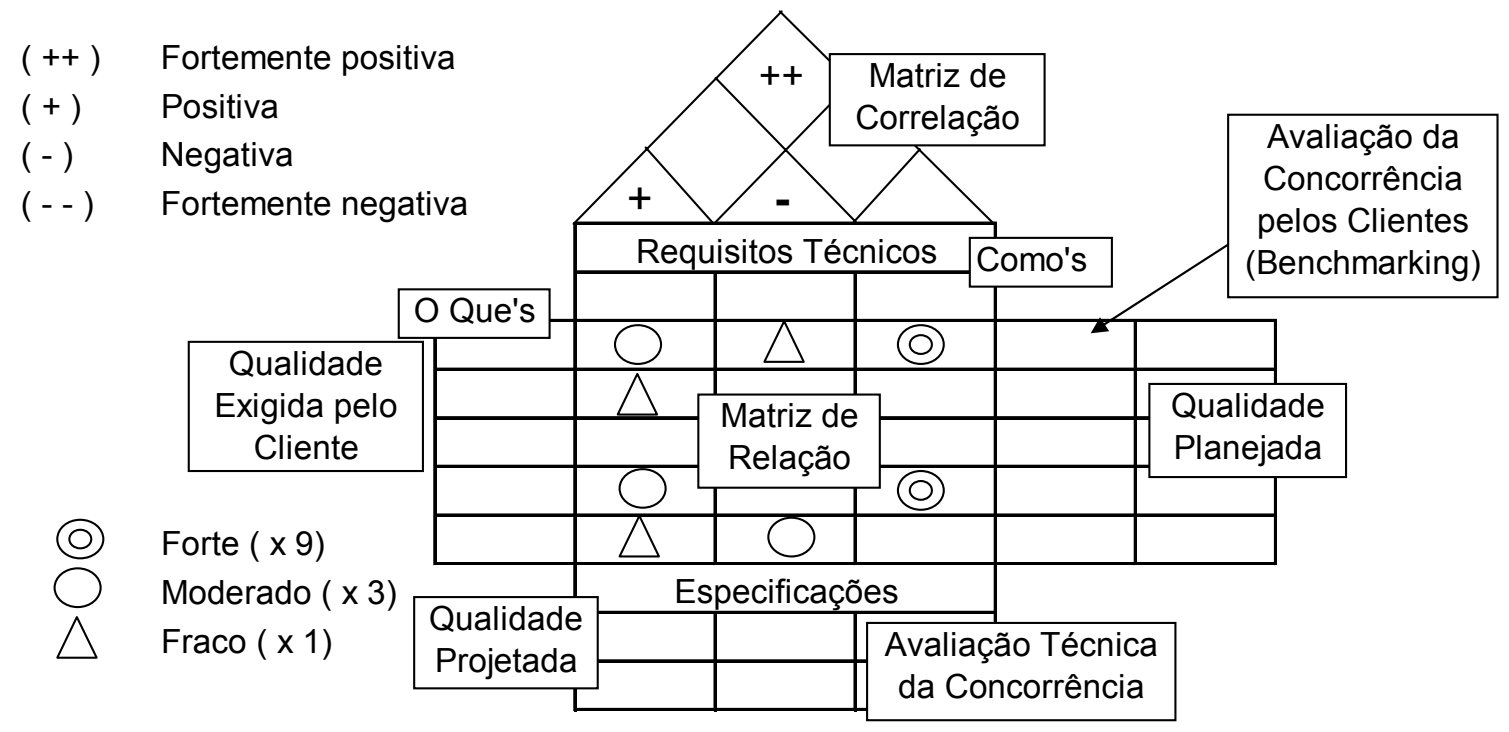

Figura 1 - Casa da Qualidade (adaptado de Mirshawka \& Mirshawka Júnior, 1994)

Segundo Govers (1996), o QFD é uma ferramenta que pode ser utilizado para desenvolvimento de novos produtos, melhoria de produtos existentes ou ainda correção de problemas detectados através de informações 
geradas pelos clientes. Segundo o autor a implementação da matriz ou casa da qualidade obedece às etapas: estabelecimento do projeto a ser executado e do produto/serviço a ser desenvolvido ou aprimorado; determinação do público-alvo e das necessidades em relação ao produto; coleta de informações sobre as exigências dos clientes; entrevistas com os clientes para designação das características exigidas, intitulado "O que" e o grau de importância de cada item; avaliação da concorrência realizado pelos clientes (qualidade planejada); desdobramento das qualidades exigidas pelos clientes em requisitos técnicos, intitulado "Como"; correlação entre as qualidades exigidas e os requisitos técnicos; determinação das metas a serem atingidas; avaliação técnica da concorrência realizado pela equipe técnica; matriz de relação ou telhado da matriz da qualidade.

\subsubsection{Montagem da Casa da Qualidade}

A primeira etapa da implementação do método QFD segundo Govers (1996) consiste em ouvir e compreender as expectativas dos clientes, através de entrevistas exploratórias. Ë fundamental detalhar o público-alvo (cliente), que segundo Mirshawka \& Mirshawka Júnior (1994) podem ser definidos em três tipos: clientes internos, intermediários e externos.

Como parte das técnicas de Gestão da Qualidade, a aplicação do QFD depende do envolvimento proveniente de várias funções na empresa para definição da equipe multifuncional, possibilitando com que cada participante dentro de sua especialidade, possa contribuir com conhecimentos técnicos e experiência, além do processo não ficar centralizado em um único indivíduo ou setor da empresa (Miguel \& Weidmann, 1999).

A etapa de obtenção das informações dos clientes é muito importante para o conhecimento das necessidades dos consumidores. Na coluna da qualidade exigida, também chamada "O quês", os itens são expressos conservando, na medida do possível a linguagem utilizada pelos clientes. 
Essas informações podem ser obtidas através de técnicas conhecidas tais como pesquisa de mercado, levantamento de marketing, entrevistas e questionários enviados via mala direta aos clientes (Akao, 1996).

O grau de importância tem papel relevante no processo QFD. Primeiramente é estabelecido o peso das qualidades exigidas pelo cliente, posteriormente estes valores são utilizados como multiplicadores de outros números da matriz (Eureka \& Ryan, 1993). Nesta etapa é importante a análise da concorrência na visão do cliente, com detalhamento da avaliação das características exigidas (Govers, 1996).

Através da Qualidade Exigida pelos clientes é determinada os Requisitos Técnicos (Comos) da matriz da qualidade, tornando as qualidades verdadeiras em características mensuráveis. Não é viável conceber um produto ou serviço que satisfaça de modo completo todas as necessidades identificadas. Portanto é preciso estabelecer prioridades, com base na importância atribuída aos diversos requisitos identificados. Além da forma e intensidade com que os vários requisitos contribuem para a satisfação do cliente, pode nesta fase efetuar-se uma análise do grau de satisfação através da utilização do diagrama de Kano (Akao, 1996)

A Matriz de Relação ou Matriz de Qualidade é posicionada no centro do modelo QFD (Casa da Qualidade), fornecendo a relação de cada Qualidade Exigida (O que) com cada Requisito Técnico (Como) (Guinta \& Praizler, 1993).

Quando existe uma relação entre uma Qualidade Exigida e um Requisito Técnico é determinado um símbolo, cuja ponderação é demonstrada na figura 2. 


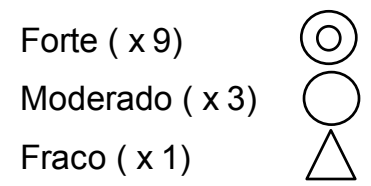

Figura 2 - Símbolos e valores utilizados para definição do grau de relação das qualidades exigidas e os requisitos técnicos

A qualidade planejada faz, através das exigências de qualidade, feito pelos clientes o comparativo ou "benchmark" das empresas que trabalham com a mesma linha de produtos. As metas de melhoria são executadas através das prioridades atribuídas pelos clientes neste comparativo (Akao, 1996).

$\mathrm{Na}$ qualidade projetada atribui-se o "benchmark" dos requisitos técnicos, sob o ponto de vista técnico. As melhorias são projetadas visando proporcionar satisfação ao clientes da empresa (Guinta \& Praizler, 1993).

A avaliação técnica da concorrência, que é semelhante à avaliação da concorrência feita pelo cliente, mas envolve detalhes técnicos do produto ou serviço, e os valores visados (Quantos), mediante os quais as especificações de engenharia são estabelecidas. Enquanto na avaliação da concorrência pelo cliente os clientes fornecem dados para a avaliação, na avaliação técnica da concorrência são os engenheiros e técnicos da empresa que fornecem dados para a avaliação (Guinta \& Praizler, 1993).

A matriz de correlação (telhado) da casa da qualidade mostra relações positivas e negativas entre os requisitos técnicos (Comos) especificados, ou seja, é utilizado para determinar quando um requisito está em conformidade com os demais. O telhado ainda indica onde pode haver necessidade de esforços adicionais de pesquisa e desenvolvimento. $O$ uso do telhado pode ajudar a identificar um recurso que pode ser utilizado para fins múltiplos. Isso é 
extremamente útil, pois essas relações raramente são identificadas ou documentadas por outro meio (Mirshawka \& Mirshawka Jr, 1994).

Miguel et al (2003) utilizaram o Desdobramento da Qualidade no desenvolvimento de filmes flexíveis de polipropileno (BOPP) para embalagens. O trabalho apresentou alguns aspectos da introdução do método na empresa, apontando as dificuldades encontradas, resultados e benefícios decorrentes da implantação. Dentre os benefícios gerados, destacou-se a importância do papel do QFD como um método para sistematizar o processo de desenvolvimento e a geração de benefícios para a equipe.

Com a abordagem na gestão de projetos no desenvolvimento de produtos moveleiros, Talmasky (2002) utilizou o desdobramento da função qualidade (QFD). O autor afirma que os componentes na gestão de projetos moveleiros devem contemplar a perspectiva de integração máxima, onde cada setor entende e incorpora às suas estratégias a necessidade de atuar como parte de um sistema, modificando o modelo tradicional de desenvolvimento do processo de produção da industria moveleira para um novo modelo de produção com menor numero de etapas, menor variabilidade de resultados, maior flexibilidade e transparência em todas as fases, vantagens essas proporcionadas com a adoção do método QFD.

\subsubsection{Aplicações do método QFD na agropecuária}

Segundo Carnevalli et. al (2003) o método QFD tem alcançado sucesso em várias áreas, principalmente na indústria, para desenvolvimento de serviços e novos produtos. Na área de serviços observou que $8,1 \%$ dos trabalhos eram aplicados na saúde, $5,4 \%$ no ensino e $2,7 \%$ nos casos relativos à telecomunicação, Internet, clubes, shopping centers, serviços automotivos entre outros. Para desenvolvimento de produtos, as aplicações mais freqüentes foram para serviços automotivos (20,8\%) e alimentos (12,5\%). Contudo a aplicação desta ferramenta na área agropecuária, apesar de trazer 
inúmeros benefícios, garantindo a qualidade do produto ou serviço, é recente e ainda pouco utilizada.

Milan \& Barros (2003) utilizaram o Desdobramento da Função Qualidade (QFD) para definição das prioridades do preparo mecanizado do solo, atendendo as exigências das mudas de Eucalyptus spp., evidenciando que os itens da qualidade exigida não possuir limitações físicas e sem restevas que limitem a mecanização foram prioritários para as mudas, sendo que a prioridade técnica foi a profundidade do sulco.

Tendo por base a simulação da qualidade da carne que um certo segmento de mercado gostaria de encontrar, Felício (1998) formulou uma matriz da qualidade, para se chegar à qualidade projetada, e outra matriz de matéria prima e processos foram construídas para se avaliar o impacto desses fatores sobre a qualidade. Os resultados foram interpretados destacando-se a importância das interações entre o tipo de matéria prima, no caso o gado de corte, e os processos ante et post mortem, como estresse e resfriamento das carcaças.

Em sua pesquisa de planejamento da qualidade do tomate de mesa, Marcos (2001) utilizou o método QFD para verificação do grau de satisfação de seus clientes. O projeto foi conduzido em um supermercado estabelecendo-se a qualidade exigida pelos consumidores. Concluiu-se que alguns itens exigidos envolviam processos simples de serem alcançados, enquanto que outros necessitavam da integração entre várias operações e aplicações de póscolheita adequada.

Com a utilização do método QFD aplicado aos cooperados (clientes internos) de três cooperativas do setor agropecuário de tamanho e localização diferentes, Guazzi (1999) testou a aplicabilidade de um modelo proposto com esta ferramenta. Os resultados obtidos ao se desdobrar os requisitos de qualidade dos clientes internos permitiu que as cooperativas proporcionassem uma maior satisfação a seus cooperados. 


\subsection{Ferramentas da qualidade}

As ferramentas da qualidade são instrumentos utilizados pelos grupos de trabalho para auxiliar de dinamizar as reuniões, elaborar projetos, padronizar atividades, organizar informações, priorizar problemas a serem resolvidos e o seu encaminhamento para soluções, contribuindo para melhor gerenciamento da atividade produtiva (Trindade et al., 2000).

As ferramentas da qualidade significaram um grande avanço, pois permitiram que os operadores no "chão da fábrica" pudessem monitorar a qualidade de seu próprio trabalho, plotando e visualizando as variações na produção. Em caso de variações muito expressivas ou freqüentes os operadores intervinham, fazendo o que era necessário para controlar a variação. Adicionalmente, possibilitou aos dirigentes saber, por intermédio da observação dos dados nos gráficos elaborados, quando o sistema se encontrava estável e quando modificações estruturais, novas tecnologias ou novos métodos se tornavam necessárias (Montgomery, 1997).

Para determinar se um processo ou produto está sob controle ou não, utilizam-se os itens de verificação, no processo e os itens de controle no produto (Dellaretti Filho \& Drumond, 1994). Os itens de verificação são indicadores que são associados às causas que operam durante o processo, isto é, são as características que influenciam o processo. Os itens de controle são indicadores que são associados aos efeitos dos processos, isto é, são as características medidas no produto acabado (Bonilla, 1994).

Com o objetivo de propor um modelo de implementação numa empresa de móveis de aço Galuch (2002) utilizou ferramentas de qualidade no processo produtivo Para identificação dos problemas foram montados diagramas de causa e efeito facilitando a visualização dos problemas relacionados ao processo produtivo. Gráfico de linhas foi utilizado como demonstrativo da quantidade de arquivos produzidos no período analisado e o gráfico de colunas mostrou os produtos fabricados pela empresa no período 
analisado. A implantação dessas ferramentas permitiu uma melhoria significativa no produto final e maior conscientização da importância das tarefas realizadas por parte dos funcionários.

\subsubsection{Aplicações das ferramentas da qualidade na agricultura}

Milan \& Fernandes (2002) avaliaram a utilização do controle estatístico de processo em operações de escarificação e gradeação para cultura do milho para silagem. A utilização do controle na operação de escarificação proporcionou da profundidade de trabalho média em $38,4 \%$ e aumento de $45 \%$ dos dados desejados. Na gradagem houve redução de $9,8 \%$ dos dados médios de tamanho dos torrões e um aumento de $75 \%$ nos torrões aceitáveis. Em ambos os casos o controle das operações permitiu a diminuição da variabilidade, obtendo resultados mais próximos aos especificados pelo corpo técnico.

Sarriés (1997) utilizou o Controle Estatístico de Processo (CEP), especialmente as ferramentas estatísticas, técnicas de amostragem e testes de hipóteses, para quantificar a quantidade de impurezas minerais em carregamentos de cana-de-açúcar, identificando os pontos críticos e corrigindo através da adequação desta ferramenta.

Avaliando a qualidade da semeadura, adubação nitrogenada de cobertura e aplicação de defensivos na cultura do milho Pasqua (1996) verificou, através da utilização de cartas de controle e histogramas os problemas decorrentes da não-padronização e a importância do controle de qualidade durante a execução das operações mecanizadas.

As cartas de controle foram utilizadas por Peche Filho et al. (2002) como ferramentas para avaliação da qualidade de subsolagem em áreas de reforma de lavouras de cana-de-açúcar. A profundidade de trabalho foi o indicador analisado, concluindo estatisticamente que o processo operacional adotado encontrava-se fora de controle nas duas áreas analisadas. 
Suguisawa (2004) analisou a estabilidade dos processos de produção da cultura do trigo, considerando seis operações mecanizadas do sistema: colheita da cultura antecessora, pulverização pré-semeadura, semeadura, adubação de cobertura, pulverização para tratamento fitossanitário e colheita. Através da utilização de cartas de controle e histogramas foram identificados os pontos que apresentaram problemas e que não se encontravam dentro das especificações agronômicas nas operações avaliadas.

Silva (1999) utilizou ferramentas de controle estatístico de processo para manutenção e melhoria de qualidade dos processos de pasteurização, desnate do leite e embaladeira em uma indústria de lacticínios. Os resultados definidos através de cartas de controle demonstraram que todos os processos encontravam-se fora de controle, necessitando de um acompanhamento sistemático para melhoria da qualidade dos produtos lácteos processados.

Fessel (2002) utilizou ferramentas da qualidade total: histogramas, diagrama de causa e efeito, gráficos de pareto e controle para avaliar as atividades de plantios manual e mecanizado de eucaliptos bem como o preparo mecanizado do solo em área pertencente a uma empresa florestal. Concluiu entre os sistemas de plantio que a distância entre plantas foi diferente estatisticamente, com melhor distribuição das mudas no sistema manual e o número de defeitos por muda transplantada foi semelhante estatisticamente entre os sistemas de plantio. 


\section{MATERIAL E MÉTODOS}

O trabalho foi realizado no viveiro de mudas da Cooperativa dos Cafeicultores da Região de Marília (Coopemar). O clima da cidade de Marília é caracterizado como mesotérmico de inverno seco, segundo a classificação de Koppen, com $49^{\circ} 95^{\prime}$ de longitude e $22^{\circ} 21^{\prime}$ de latitude sul, com temperatura mínima de $17,8^{\circ}$ e máxima de $28,5^{\circ}$ e índice pluviométrico de $1274,4 \mathrm{~mm}$ /ano.

As mudas de cafeeiros analisadas foram produzidos em tubetes plásticos de $120 \mathrm{ml}$, com substrato a base de fibra de coco e adição de fertilizantes de liberação controlada. O processo de plantio utilizado foi 0 método indireto, com utilização de germinadores de areia e posterior repicagem. A semeadura é realizada de agosto a setembro e o período de produção total é em média de 6 a 7 meses após a semeadura.

O sistema produtivo seguiu três etapas básicas determinados pelo sistema de sombreamento e irrigação: etapa 1, que contemplam mudas recémenxertadas; etapa 2, com mudas em estádio intermediário e etapa 3 , com mudas que atingem a fase final (expedição). Na primeira etapa (figura 3) as mudas recém-enxertadas, nos estádios de "orelha de onça" e "palito de fósforo" são acondicionadas, repicadas em tubetes e levadas a locais propícios para o "pegamento" ("berçário"), com alta umidade, luminosidade controlada e temperatura amena durante o período de 30 dias. Na etapa posterior (figura 4) as mudas são transferidas em locais com tela de sombreamento de $75 \%$, durante 60 dias. Na terceira etapa (figura 5) as mudas são acondicionadas em células intercaladas uma das outras e sombreamento de $50 \%$ durante 60 dias, possibilitando o desenvolvimento da muda e evitando o seu estiolamento. 
Nessa última etapa as mudas são aclimatadas ao sol pleno por 30 dias, com diminuição do turno de rega, rustificando-as para o transplantio a campo.

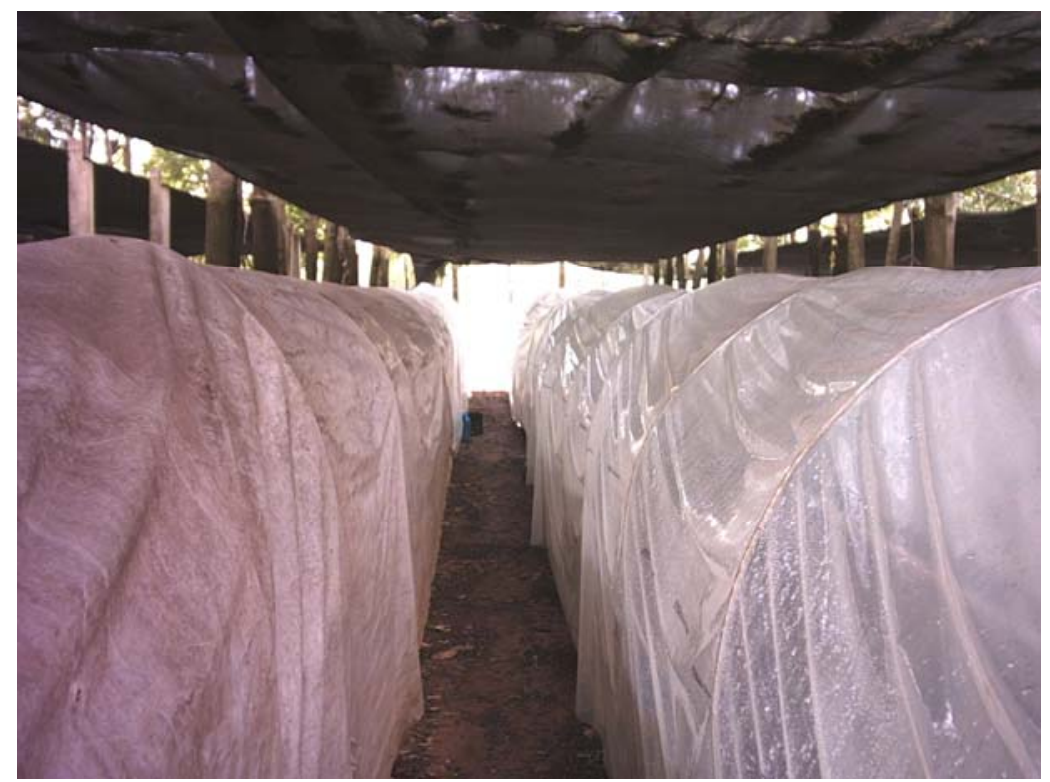

Figura 3 - Etapa 1, "berçários" onde são acondicionados muda em estádio inicial

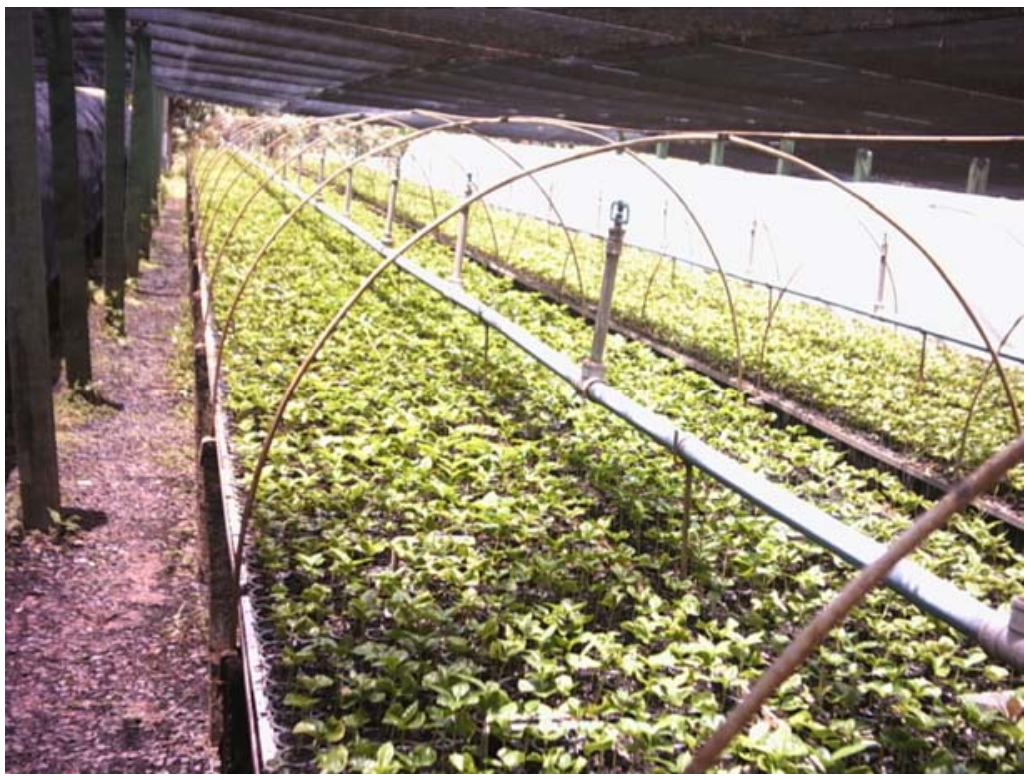

Figura 4 - Etapa 2, mudas em estádio intermediário 


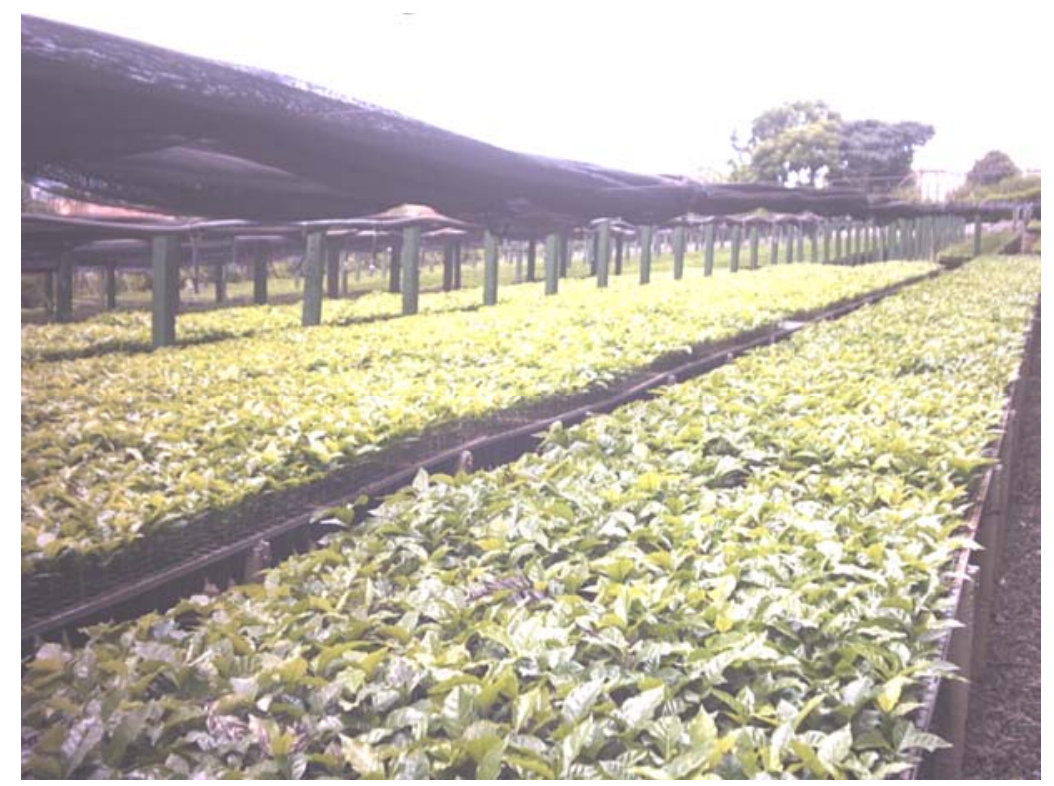

Figura 5 - Etapa 3, mudas em estádio final

\subsection{Aplicação do método QFD na produção de mudas de café}

A realização do trabalho foi composta por duas fases: aplicação do método QFD e verificação do sistema produtivo. A primeira fase foi composta de entrevistas, visando a aquisição das características desejadas pelos clientes, o grau de importância de cada item e a análise da concorrência. Nessa fase utilizaram-se os dados adquiridos para aplicação da metodologia QFD (Casa da Qualidade), verificando a melhoria requerida e os possíveis fatores interferentes do processo. A segunda fase referiu-se ao emprego de ferramentas de controle (gráficos de controle e histogramas) no sistema produtivo de mudas, verificando individualmente os indicadores de qualidade selecionados pela equipe.

O método QFD recomenda que o procedimento de implementação do QFD seja realizado com reunião de representantes de todas as partes funcionais do sistema produtivo. Com isso estruturou-se uma equipe composta por engenheiros agrônomos, responsáveis técnicos do viveiro de mudas da 
cooperativa; encarregado do sistema produtivo; cafeicultor e o responsável pela pesquisa (moderador do método QFD).

A primeira fase foi desenvolvida seguindo a metodologia de Govers (1996), estabelecendo-se a muda de café enxertada como segmentação de mercado a ser aplicado o método QFD e o público-alvo os cooperados, clientes de mudas da região de Marília, SP.

A aquisição da qualidade exigida foi composta de pré-entrevistas aos cooperados, clientes de mudas, com a finalidade de captar quais as características e serviços são considerados na aquisição das muda de café.

Para montagem da casa da qualidade seguiu-se a seqüência com a determinação da qualidade exigida (O que) pelos clientes, verificação do grau de importância de cada "O que", avaliação da qualidade exigida pelos clientes (qualidade planejada), desdobramento das qualidades exigidas ( $\mathrm{O}$ que) em requisitos técnicos (Como), determinação da relação entre "O que" e "Como", determinação da qualidade projetada pela equipe técnica e montagem da matriz de correlação ou telhado.

As entrevistas foram aplicadas individualmente com os proprietários, clientes das mudas de café da cooperativa ou através dos responsáveis pelo recebimento e manejo das mudas e da lavoura cafeeira. Foram utilizadas nas entrevistas técnicas qualitativas, por permitir a geração de idéias e aprofundamento no ponto de vista do usuário do produto, usando expressões simples e com apenas um significado, segundo metodologia de Cheng (1995). O objetivo principal foi produzir uma lista de necessidades que seja a mais ampla possível, estimulando os desejos do cliente em relação às características da muda de café.

\subsection{Construção da Tabela de Desdobramento da Qualidade Exigida}

Os itens de qualidade exigida com conteúdo similar ou idéias afins foram agrupados em um único título. A partir das respostas obtidas nas 
entrevistas da avaliação qualitativa, cada resposta foi transcrita para um papel "post-it", sendo a seguir todos os papéis organizados por afinidade, segundo metodologia utilizada por Barros (2001). Para isto, cada ficha foi lida cuidadosamente, na tentativa de captar a essência contida em cada idéia registrada. Para isso utilizou-se o diagrama de afinidades (Figura 6).

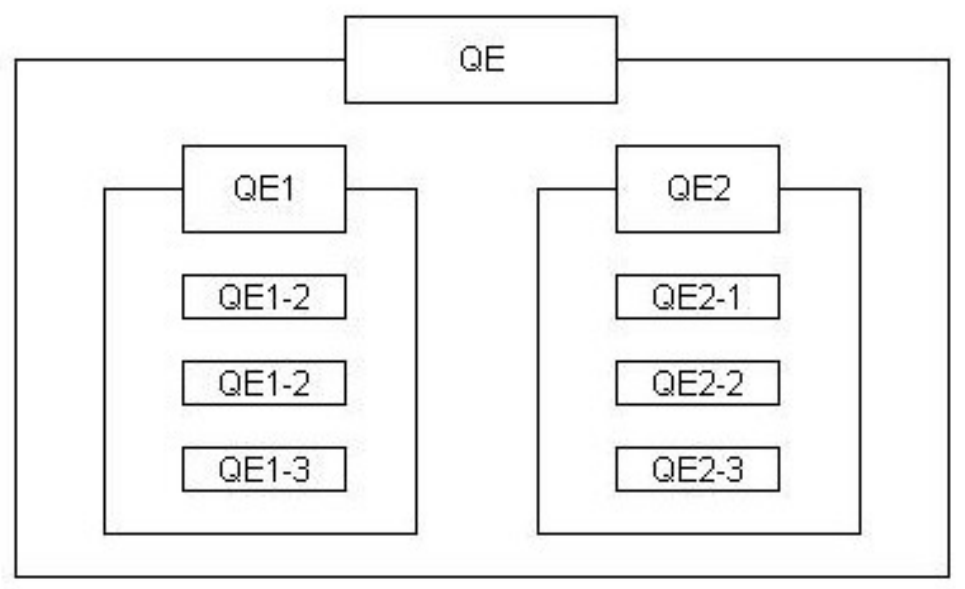

Figura 6 - Diagrama de Afinidades (adaptado de Dellaretti Filho, 1996)

A seguir esses itens agrupados, utilizando-se a técnica de diagrama de afinidades, foram organizados na forma de diagrama de árvore (Figura 7).

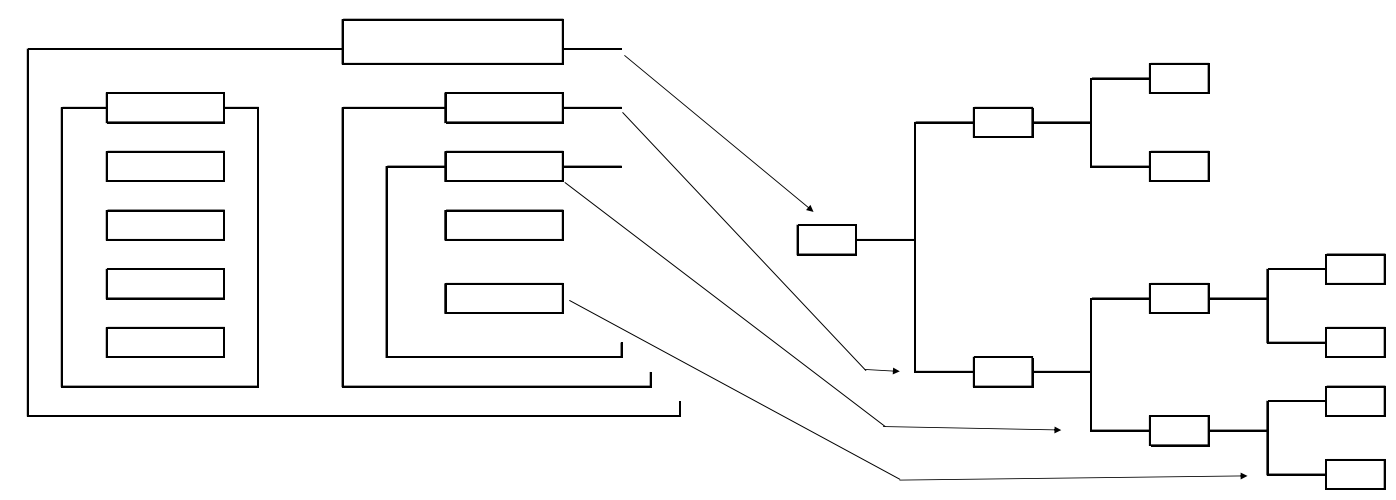

Figura 7 - Diagrama de afinidades e diagrama das árvores 


\subsection{Avaliação da qualidade exigida}

No preenchimento dos formulários, estabeleceu-se o grau de importância atribuído a cada item de qualidade avaliado pelo consumidor. Para cada item, o entrevistado atribuía um grau de importância apresentado no quadro 1.

\begin{tabular}{cl}
\hline Peso & Grau de Importância \\
\hline 1 & Nenhuma importância \\
2 & Pouca importância \\
3 & Alguma importância \\
4 & Importante \\
5 & Muito importante \\
\hline
\end{tabular}

Quadro 1 - Grau de Importância para os itens avaliados

\subsection{Qualidade planejada}

A qualidade planejada permitiu através da opinião dos clientes o desenvolvimento da melhoria contínua de cada item de característica exigida. A avaliação da concorrência foi realizada através do estabelecimento da avaliação pelos clientes da muda enxertada da cooperativa em relação à sua concorrente. Os clientes atribuíram valores (de 1 a 5) referentes a cada característica, utilizando a graduação apresentada no quadro 2. 


\begin{tabular}{cl}
\hline Peso & Grau de satisfação \\
\hline 1 & Péssimo \\
2 & Ruim \\
3 & Regular \\
4 & Bom \\
5 & Ótimo
\end{tabular}

Quadro 2 - Grau de satisfação dos itens avaliados

O plano de melhorias foi realizado através da estipulação dos valores para cada qualidade exigida pela equipe, analisando o grau de importância e a avaliação comparativa com o concorrente.

O índice de melhorias para cada item de qualidade exigida foi determinado através da divisão do plano de melhoria pela avaliação estipulada pela entrevista aos clientes de mudas.

Destaque no mercado significa se determinada qualidade exigida possui item atrativo para competitividade no mercado. Os valores são 1,0 para característica que não possua destaque no mercado e 1,2 para itens com itens atrativos.

O peso absoluto da qualidade exigida (PA) é resultado do grau de importância (GI), do índice de melhoria (IM) e do destaque do mercado (D) de cada item (eq.1).

O peso relativo (PR) composto pelo peso absoluto da qualidade exigida e a somatória dos pesos absolutos (eq. 2).

$$
\begin{aligned}
& P A=G I \times I M \times D \\
& P R=P A /(\Sigma P A) \times 100
\end{aligned}
$$




\subsection{Extração da qualidade exigida para características da qualidade}

Para se executar o desdobramento da qualidade exigida para requisitos técnicos definiu-se, para cada elemento da tabela original, qual é o elemento correspondente na nova tabela. Assim para cada qualidade exigida identificaram-se as características da qualidade que podem ser medidas no produto final para se avaliar o atendimento às exigências dos clientes. Nessa fase foi utilizada a técnica de brainwritting para geração das características da qualidade, escrevendo cada item extraído em um post-it.

A partir do objetivo básico, definiram-se os meios ou estados mais diretamente ligados a ele. Esses meios são medidas que podem ser tomadas para a sua realização (características mensuráveis ou controláveis). A definição dos meios mais gerais pode ser feita por meio das respostas às perguntas:

- "O que fazer?" A resposta deve ser o objetivo;

- "Como fazer?" A resposta será o meio, mais geral possível, para se caminhar em direção ao objetivo.

Nesse esquema (Figura 8) a pergunta "como fazer?" foi repetida até que se esgotassem todos os meios possíveis. 


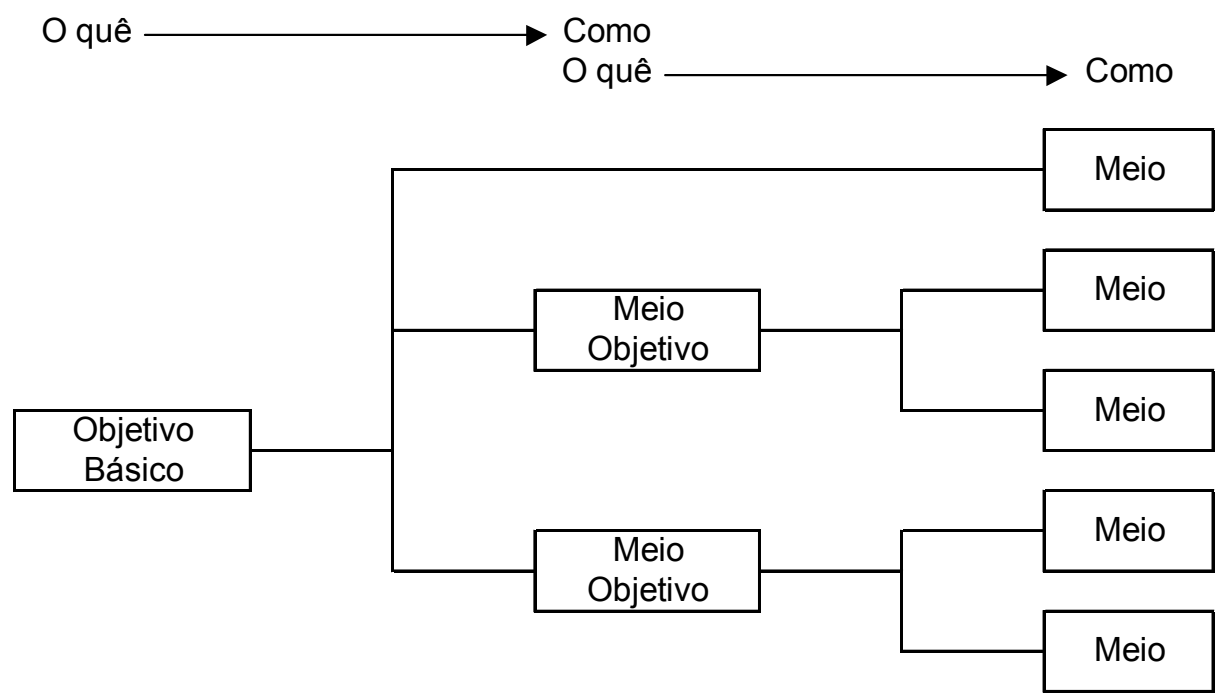

Figura 8 - Determinação dos Meios Secundários

$\mathrm{Na}$ extração da qualidade exigida para características da qualidade os itens agrupados através do diagrama de afinidades são reagrupados por meio de diagramas de árvores, através de temas ou itens-chave (figura 9). 


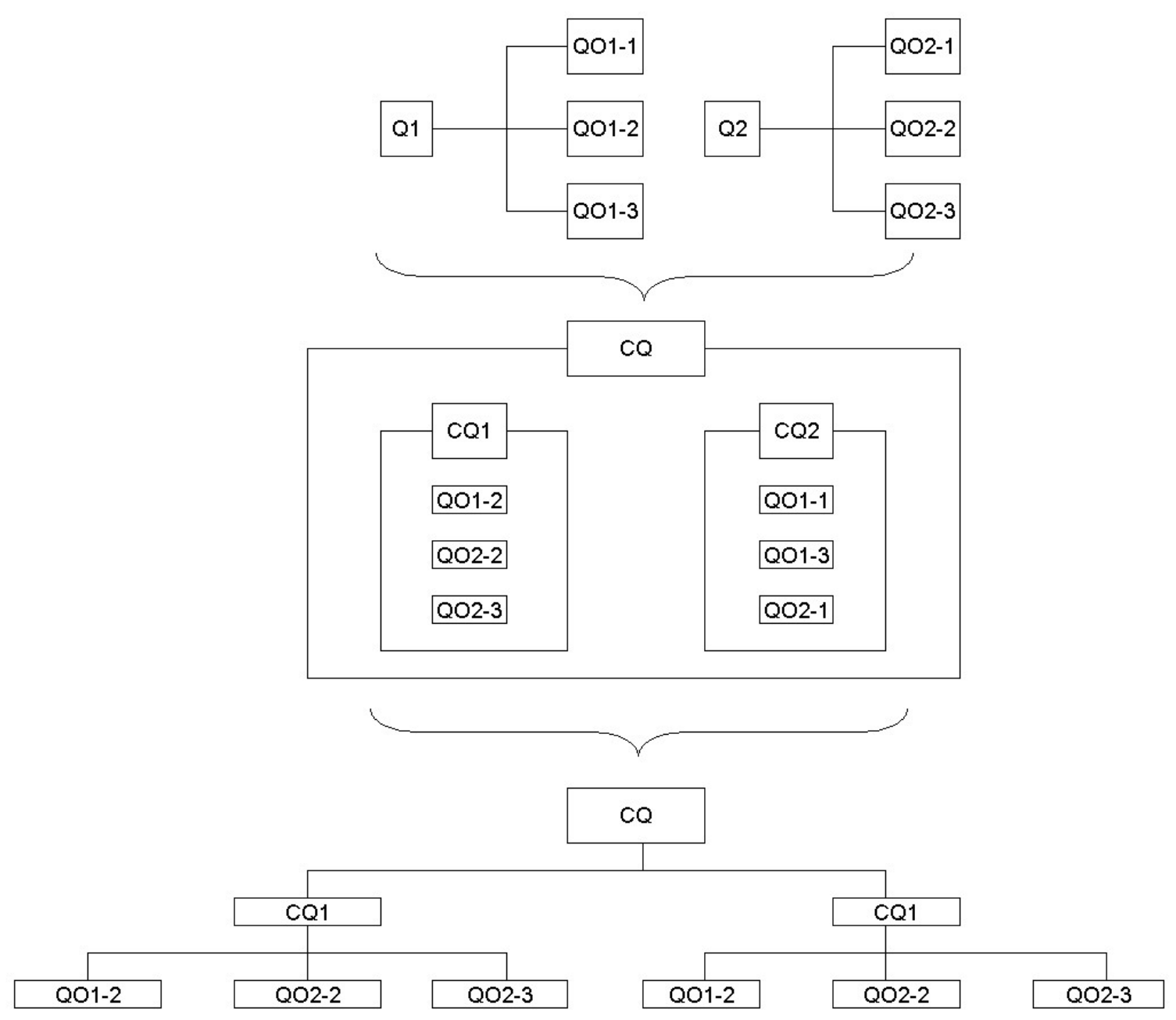

Figura 9 - Extração da Qualidade Exigida para Características da Qualidade

Após definição de todos os meios primários, foram analisados a fase de avaliação da sua adequação ao objetivo e de sua viabilidade. Quanto à viabilidade, eles foram classificados como:

- viáveis;

- inviáveis.

Os meios não-adequados foram eliminados, mantendo-se apenas os meios viáveis. Em geral os meios secundários não são ações executáveis, portanto é necessário desdobrá-los em ramos secundários. Nesse novo 
desdobramento, transforma-se cada meio primário no objetivo de uma nova árvore e repete-se o procedimento anterior.

\subsection{Correlação entre as características da qualidade e qualidade exigida}

Para a identificação do nível de inter-relação entre as características da qualidade com as qualidades exigidas foram realizados encontros entre os membros das equipes. Adotou-se características com correlação forte, moderada e fraca, com pesos de 9, 3 e 1, respectivamente.

A correlação foi realizada através do consenso da equipe, preenchendo individualmente as correlações e argumentando, em caso de divergências.

\subsection{Qualidade projetada}

A qualidade projetada são os requisitos técnicos necessários para definição do projeto do produto. Essa etapa da construção da casa da qualidade integrou os pesos absolutos e relativos, classificação dos requisitos técnicos, avaliação das especificações e objetivos técnicos relacionados à qualidade das mudas de café, considerando restrições relativos à tecnologia e acréscimo de custos de produção.

Os pesos absolutos de cada requisito técnico foram obtidos através da utilização da "voz do cliente" determinado pelo grau de importância (GI), índice de melhoria (IM) e ao argumento de vendas (AV) segundo as eq. (3) e (4).

$$
\begin{aligned}
& P A=G I \times I M \times A V \\
& P R=P A /(\Sigma P A) \times 100
\end{aligned}
$$


As especificações técnicas foram obtidas juntamente com a equipe, estabelecendo tecnicamente as características de cada requisito e seu comparativo com a concorrência.

\subsection{Matriz de correlações}

Os requisitos técnicos utilizados na casa da qualidade foram correlacionados entre si na matriz de correlações ou telhado da casa da qualidade, para definição das prioridades e da cooperação ou não de cada item. Essas correlações foram obtidas através de pesos atribuídos, podendo ser avaliados como: positiva forte; positiva fraca; negativa fraca; negativa forte, respectivamente.

\subsection{Itens de controle do sistema produtivo}

A partir da classificação dos requisitos técnicos, obtidos na qualidade projetada, selecionou-se em conjunto com a equipe técnica os itens de controle a serem verificados nas mudas de café. $O$ objetivo foi avaliar as características das mudas de café em campo, com a utilização de cartas de controle de média e amplitude e histogramas para diagnóstico da faixa de produção. Para implantação dessas ferramentas utilizou-se o programa Microsoft Excel ${ }^{\circledR}$.

Para confecção da carta de controle das médias, o limite médio (LM) foi estipulado através da média geral da amostra. O limite superior de controle (LSC) e o limite inferior de controle (LIC) foram calculados através da seguinte eq. (5) e (6).

$$
\begin{aligned}
& L S C=L M+A 1 \times R \\
& L I C=L M-A 2 \times R
\end{aligned}
$$


Onde A1 e A2 são constantes tabeladas em função do número de amostras e R é a amplitude global das amostras.

Nas cartas de controle da amplitude, o limite superior de controle (LSC) e o limite inferior de controle (LIC) foram calculados através da eq. (7) e (8).

$$
\begin{aligned}
& L S C=D 4 \times R \\
& L I C=D 3 \times R
\end{aligned}
$$

Onde D3 e D4 são constantes tabeladas estatisticamente, em função do tamanho da amostra e R a amplitude global das amostras.

\subsection{Avaliação dos parâmetros selecionados}

A determinação dos parâmetros de diâmetro do caule e altura da planta foram realizados no dia 20/11/04 e a massa seca da muda e do substrato foram realizados no dia 06/12/04 com mudas após 30 dias de enxertia.

\subsubsection{Determinação do estado nutricional}

A determinação do estado nutricional das mudas de café foram realizadas pelo técnico responsável pelo viveiro de mudas, optando-se por seguir uma escala prática (Quadro 3), seguindo as recomendação de Sera (2004), com a seguinte ponderação: 


\begin{tabular}{ll}
\hline Escala & Características \\
\hline 1 - Ruim & Folhas amarelas pequenas e caídas \\
2 - Regular & Folhas amareladas, tamanho médio/superior e não-caídas \\
3 - Bom & Folhas verdes sem brilho, tamanho médio e espessura fina \\
$4-$ Ótimo & Folhas verde escuras, tamanho médio e espessas \\
5 - Excelente & Folhas verde escuras, médias ou superior e espessas \\
\hline
\end{tabular}

Quadro 3 - Características nutricionais das mudas de café

\subsubsection{Determinação da Massa Seca}

Após a lavagem, as diferentes partes das plantas (raízes e parte aérea) foram acondicionadas em sacos de papel devidamente etiquetados e perfurados, para posterior secagem em estufa de circulação forçada de ar, a $60-70^{\circ} \mathrm{C}$, por 36 horas. A determinação da massa seca foi efetuada em balança eletrônica com precisão de $0,01 \mathrm{~g}$.

\subsubsection{Altura da planta}

A altura da muda de café foi determinada a partir do nível do substrato, na região do colo da planta até a inserção do último par de folhas expandidas com utilização de trena.

\subsubsection{Diâmetro do caule}

O diâmetro do caule das mudas foi determinado utilizando-se um paquímetro, obtendo as medidas na região localizada abaixo da inserção das folhas cotiledonares. 


\subsubsection{Massa seca de substrato por tubete}

A determinação da massa seca de substrato alocado por tubete teve como objetivo avaliar a homogeneidade de distribuição da mesa vibratória. Para isso foi realizado a coleta do substrato nas bandejas alocadas na fase de repicagem e seco em estufa por 36 horas a $65^{\circ} \mathrm{C}$, medindo sua massa posteriormente com balança de precisão.

\subsubsection{Profundidade de transplantio em tubete}

A profundidade de transplantio foi determinada através da retirada da muda de café do tubete, após o processo de plantio, verificando a sua medida através de um paquímetro. 


\section{RESULTADOS E DISCUSSÃO}

A matriz da qualidade apresentado na Figura 5 representa a sistematização do planejamento de produção de mudas de café utilizando o método QFD para estabelecimento das características a serem obtidas da muda de café. A matriz foi decomposta em 6 etapas (Quadro 4) para análise detalhada, seguindo a metodologia de Govers (1996).

\begin{tabular}{ll}
\hline Etapa & Parte constituinte \\
\hline 1 & Qualidade Exigida \\
2 & Qualidade Planejada \\
3 & Características da Qualidade \\
4 & Matriz de Relação \\
5 & Qualidade Projetada \\
6 & Matriz de Correlação \\
\hline
\end{tabular}

Quadro 4 - Etapas e partes constituintes da matriz da qualidade

\subsection{Qualidade exigida e Grau de importância (Etapa 1)}

A partir do questionário aplicado aos clientes de mudas de café da cooperativa obteve-se a lista das qualidades exigidas. Os itens sugeridos e avaliados no questionário foram divididos em três grandes grupos: Planta, Material e Métodos. O grupo Planta foi subdividido em três subgrupos, englobando as características da parte aérea, raízes e sanidade. $O$ grupo Material engloba dois subgrupos formados pelas características do substrato e 
recipiente utilizado. O grupo Métodos foi composto pelas características relacionadas intrinsecamente com o modo de produção e expedição da muda.

O subgrupo parte aérea foi composto por 8 qualidades exigidas pelos clientes, sendo composto por itens inerentes ao caule, folhas e qualidade do enxerto realizado na muda. O subgrupo raízes foi constituído por 3 itens relacionados à estruturação das raízes e o subgrupo Sanidade por 3 fatores de sanidade.

Os subgrupos substrato e recipiente foram caracterizado por fatores relacionados com o substrato utilizado e a constituição, formato e reutilização do recipiente. O subgrupo Serviço, constituído por 7 itens foi caracterizado pelos serviços oferecidos pré e pós-venda e os termos de pagamento.

O grau de importância determinado pelos clientes demonstraram os itens caule retilíneo, enxerto bem-feito, raiz pivotante retilínea, sem pragas e doenças e bem adubada como exigências "muito importante" para caracterização da muda de café, com avaliação 5 . 

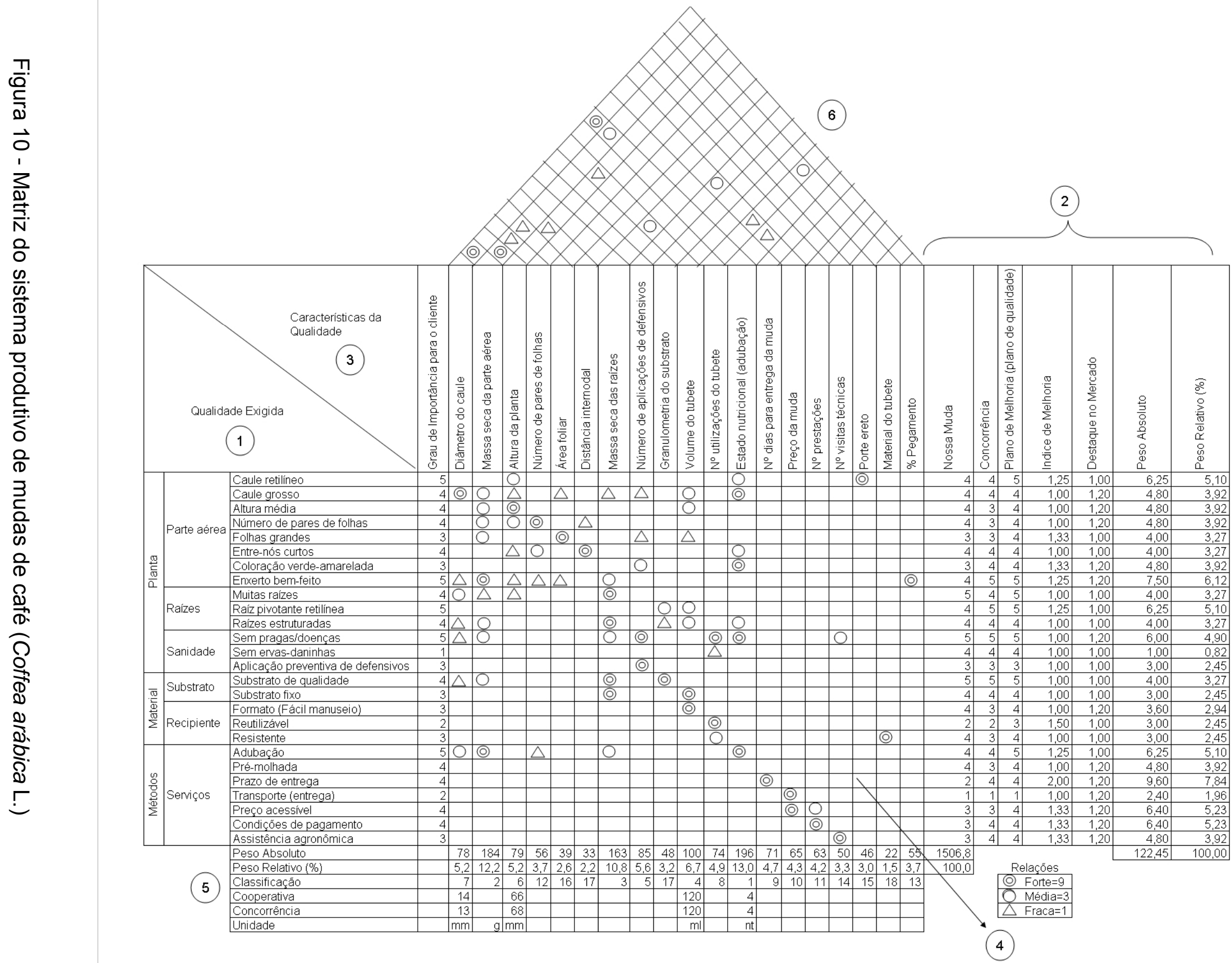


\subsection{Qualidade planejada (Etapa 2)}

A qualidade planejada é uma análise crítica das características da muda de café e dos serviços que a cooperativa está oferecendo a seus clientes. Os quatro itens que obtiveram maior pontuação relativa nessa etapa foram prazo de entrega, com 7,84 \%; enxerto bem-feito (6,12 \%); preço acessível e condições de pagamento da muda (5,23 \%); caule retilíneo, raiz pivotante retilínea e adubação com $5,10 \%$ cada.

O comparativo com a concorrência foi realizado procurando determinar a avaliação para cada qualidade exigida pelo cliente. A muda produzida na cooperativa, intitulada na matriz como "Nossa Muda" obteve resultados gerais superiores à concorrência, porém nos itens enxerto bemfeito; raiz pivotante retilínea; prazo de entrega; condições de pagamento e assistência agronômica a muda concorrente obteve avaliação superior em relação à "Nossa Muda".

\subsection{Requisitos técnicos (Etapa 3)}

A partir do desdobramento da qualidade exigida, a equipe definiu os indicadores de qualidade que preencheriam as necessidades dos clientes de mudas de café. Foram selecionados 19 itens. Todas as características da qualidade alocadas nessa etapa foram baseadas em fatores mensuráveis.

\subsection{Relação entre qualidade exigida e requisitos técnicos (Etapa 4)}

A matriz de relação identifica o nível de relação ou dependência entre uma qualidade exigida e o requisito técnico.

Dentre as qualidades exigidas o caule grosso, raízes estruturadas, sem pragas e doenças e bem adubada foram os itens que obtiveram as maiores correlações. Nos requisitos técnicos. 
Para as características da qualidade o diâmetro do colo da muda, massa seca da parte aérea e a massa seca das raízes foram os indicadores que possuíram o maior número de correlações com a qualidade exigida pelos clientes.

\subsection{Qualidade projetada (Etapa 5)}

Os indicadores de qualidade nessa etapa foram classificados segundo o peso relativo obtido para cada característica da qualidade, evidenciando através da equipe técnica os itens que mereceram destaque. A classificação, em ordem crescente apresentou os seguintes indicadores de qualidade:

1. Estado nutricional (adubação);

2. Massa seca da parte aérea;

3. Massa seca das raízes;

4. Volume do tubete;

5. Número de aplicação de defensivos;

6. Altura da planta.

7. Diâmetro do caule; 
A partir da classificação dos requisitos técnicos, e análise da viabilidade econômica e funcional do sistema produtivo de mudas os seguintes itens foram dispostos à verificação:

- $\quad$ Estado nutricional (adubação);

- Massa seca da parte aérea;

- Massa seca das raízes;

- $\quad$ Altura da planta;

- $\quad$ Diâmetro do caule;

Os itens volume do tubete e número de aplicação de defensivos foram excluídos do sistema produtivo por serem características inviáveis técnica e economicamente pela estrutura da cooperativa.

\subsection{Matriz de correlação (Etapa 6)}

A matriz de correlação ou telhado da casa da qualidade apresentou a relação existente entre os indicadores de qualidade. $\mathrm{O}$ indicador diâmetro do caule obteve duas fortes correlações com a massa seca da parte aérea e o estado nutricional (adubação). Outra forte correlação foi obtida da massa seca da parte aérea com a altura da planta. Esses itens por merecer destaque nas correlações analisadas e serem determinantes para fins múltiplos.

\subsection{Avaliação dos indicadores desdobrados}

\subsubsection{Estado nutricional}

O gráfico de controle da média para análise do estado nutricional das mudas de café, com valores de 1 a 5 é apresentado na Figura 11. No intervalo de 3 a 5 notou-se valores ligeiramente superiores em relação à média, e nos intervalos de 6 a 10 observou-se uma ligeira tendência negativa das amostras 
em relação à média. Apesar de apresentar oscilações nos intervalos analisados, o processo encontrou-se sob controle.

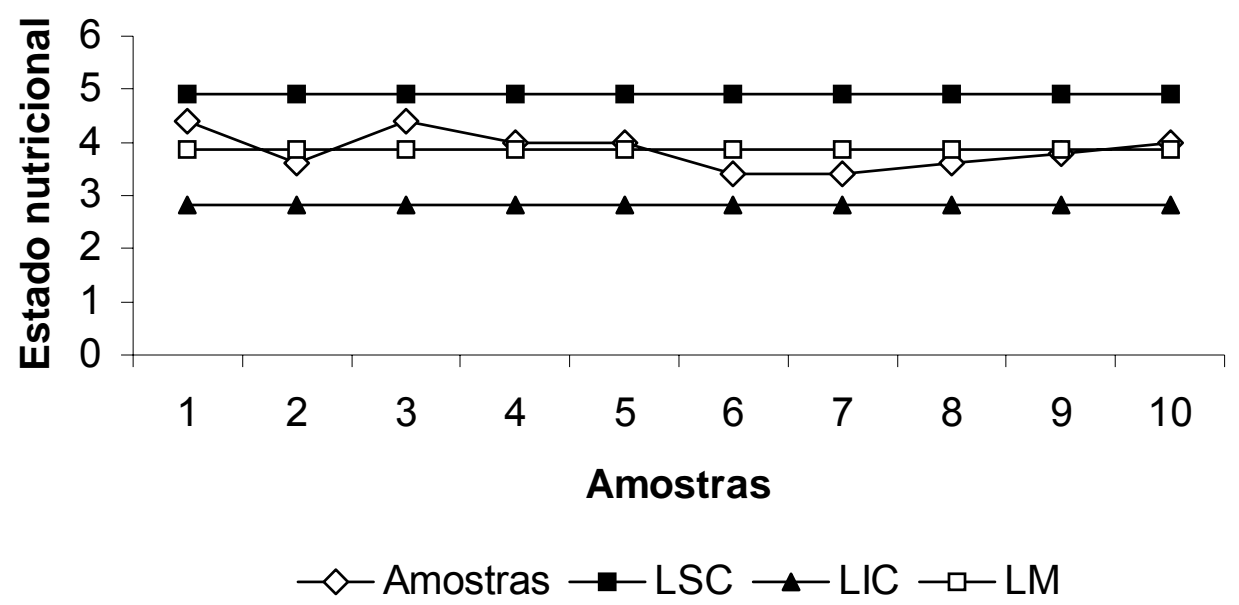

Figura 11 - Avaliação do estado nutricional das mudas de café

Analisando o gráfico de controle da amplitude (Figura 12) do estado nutricional notou-se que o processo se encontrava sob controle. As amostras 1, 4, 7 e 8 encontraram-se abaixo do limite médio, e duas amostras (6 e10) acima do limite médio. As demais amostras analisadas apresentaram valores próximos a 1,8 (LM). 


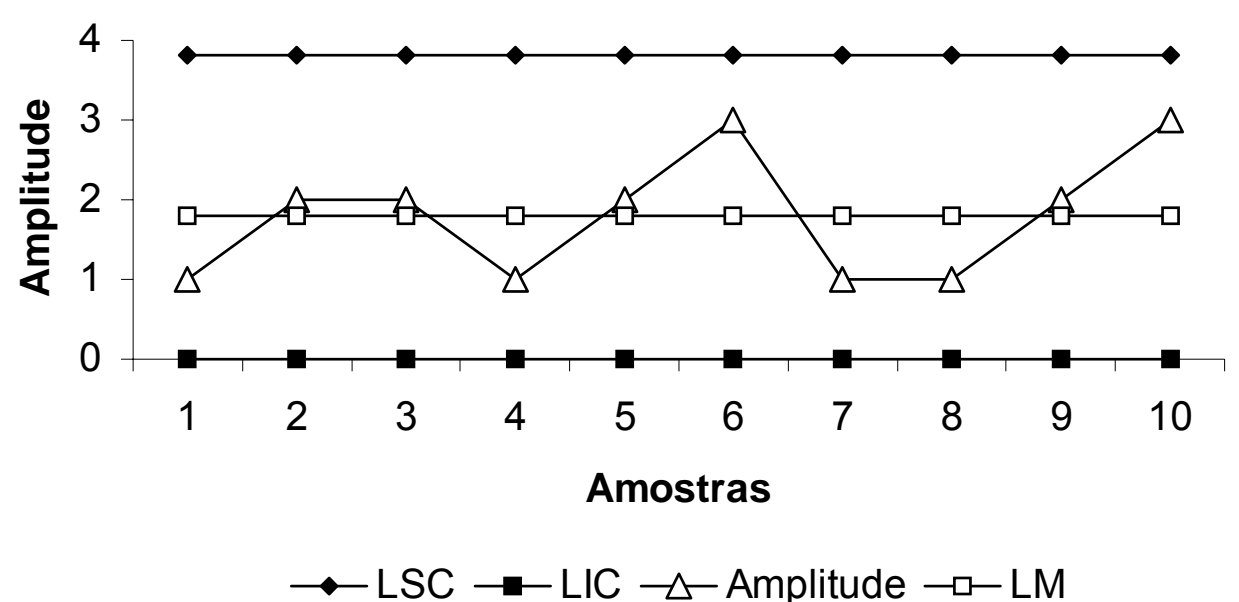

Figura 12 - Amplitude do estado nutricional das mudas

\subsubsection{Altura}

Na Figura 13 é apresentado o gráfico de controle para a altura das mudas de café. A média obtida foi de $661,3 \mathrm{~mm}$, variando entre $636 \mathrm{~mm}$ e $715,8 \mathrm{~mm}$. Observou-se que os valores se apresentaram dentro dos limites de controle com ligeira tendência negativa nos intervalos 3 a 5 e 7 a $10 . \mathrm{Na}$ amostra 6 a altura apresentou um abrupto acréscimo da altura das mudas analisadas. 


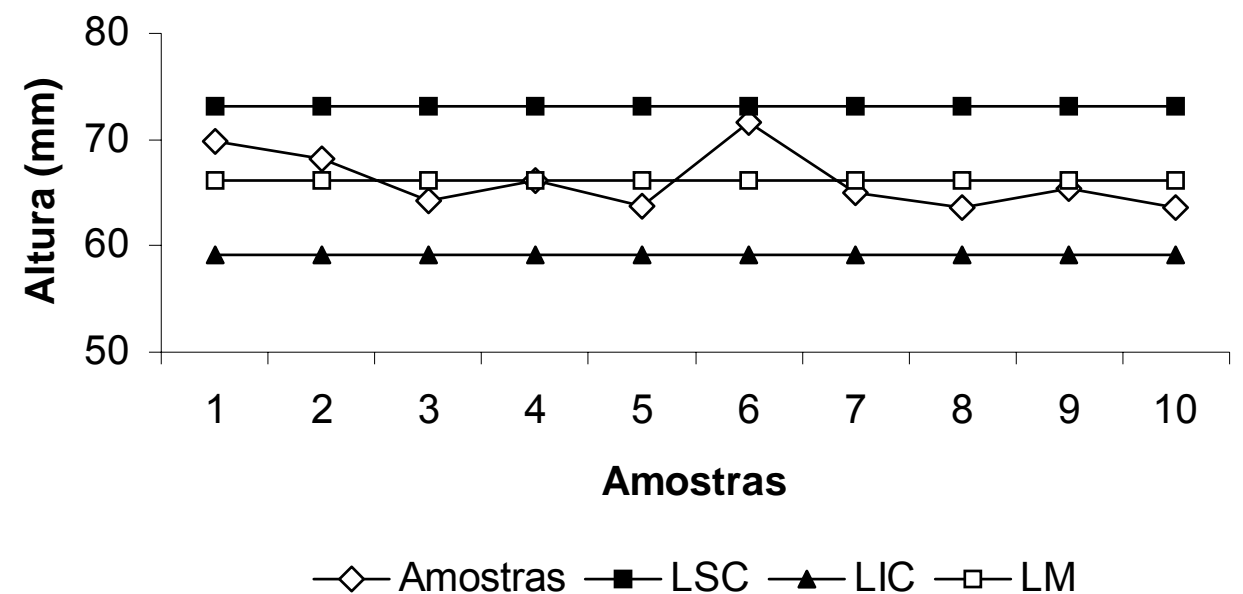

Figura 13 - Gráfico de controle para a altura das mudas

Para o gráfico de controle da amplitude da altura da muda (Figura 14) observou-se no intervalo de pontos de 3 a 8 uma tendência de diminuição da amplitude, seguido de uma alteração brusca especialmente no ponto 9 , porém dentro dos limites de controle estabelecidos.

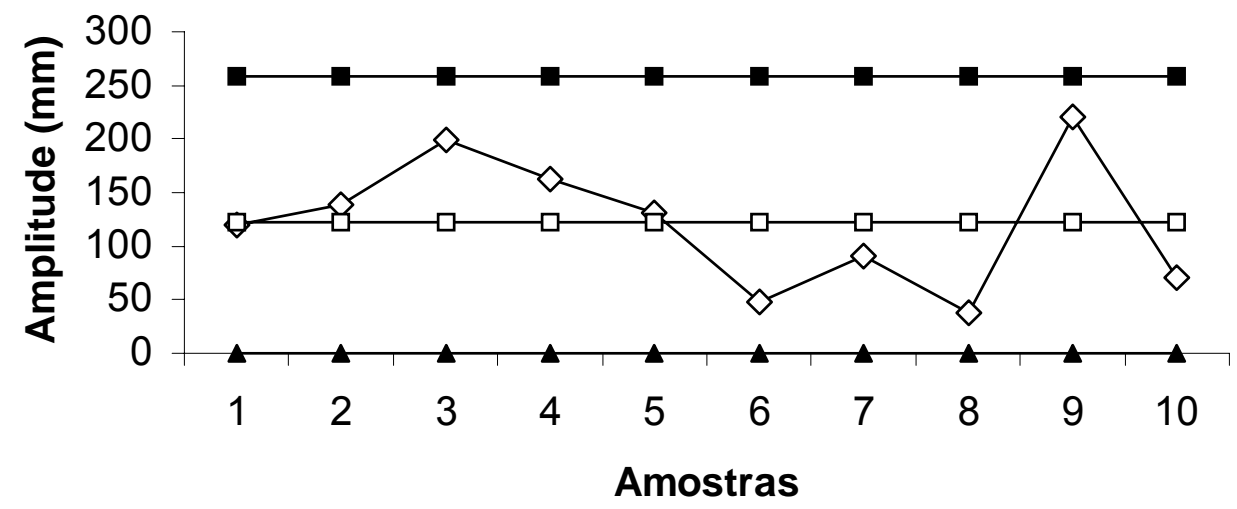

$\rightarrow$ LSC $\neg$ LIC $\diamond$ Amplitude $\rightarrow-\mathrm{LM}$

Figura 14 - Gráfico de controle da amplitude para altura das plantas 
Na Figura 15 é apresentado o histograma de distribuição referente à altura das mudas de café. As mudas apresentaram $88 \%$ das medidas de altura dentro dos limites de controle $(59,09 \mathrm{~mm}$ a $73,17 \mathrm{~mm})$.

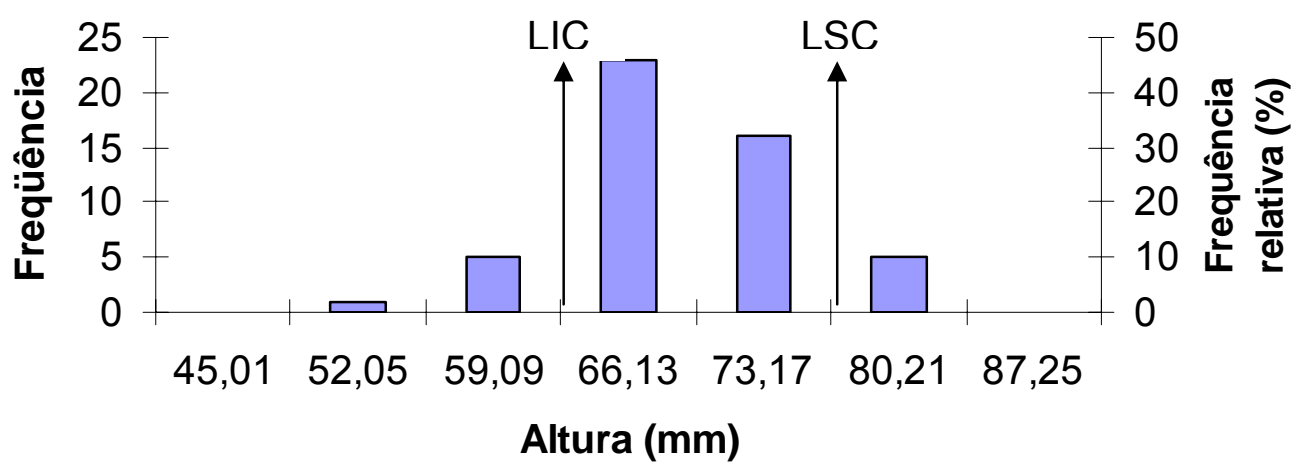

Figura 15 - Histograma da altura das mudas de café

\subsubsection{Diâmetro do caule}

Para análise do diâmetro do caule a carta de controle das médias (Figura 16) apresentou-se dentro do controle, evidenciando uma tendência abaixo do limite médio (LM) nos intervalos de 2 a 5 e de 8 a 10.

Para análise da amplitude nos intervalos de 5 a 8 o gráfico (Figura 17) apresentou amplitudes acima da média, determinando variações de diâmetros nas amostras coletadas, porém dentro dos controles estabelecidos. 


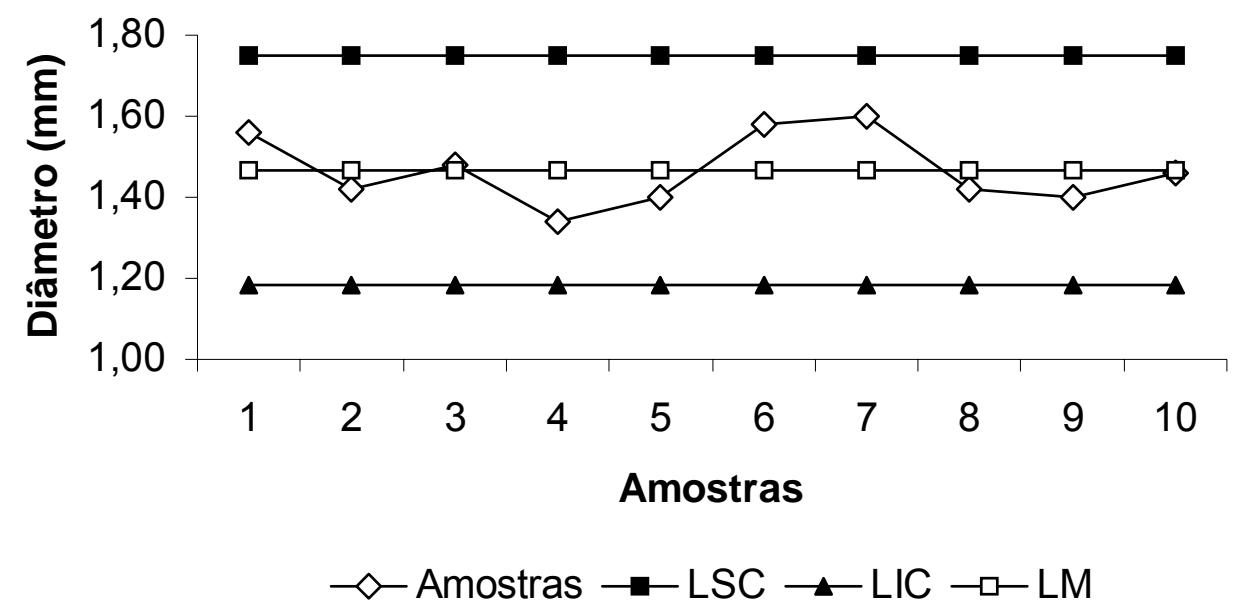

Figura 16 - Gráfico de controle da média para diâmetro do caule da planta

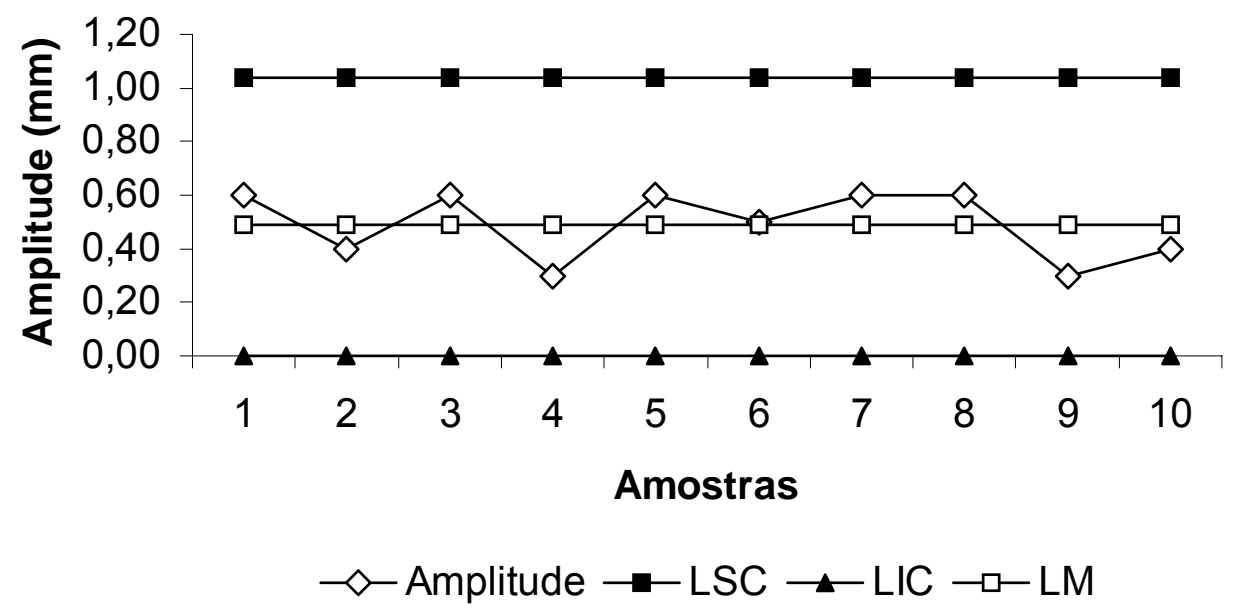

Figura 17 - Gráfico de controle da amplitude para diâmetro do caule da planta

No histograma (Figura 18) referente à mensuração do diâmetro do caule da muda de cafeeiro notou-se que $88 \%$ das medidas foram observadas dentro dos limites de controle, com $12 \%$ acima do limite superior. 


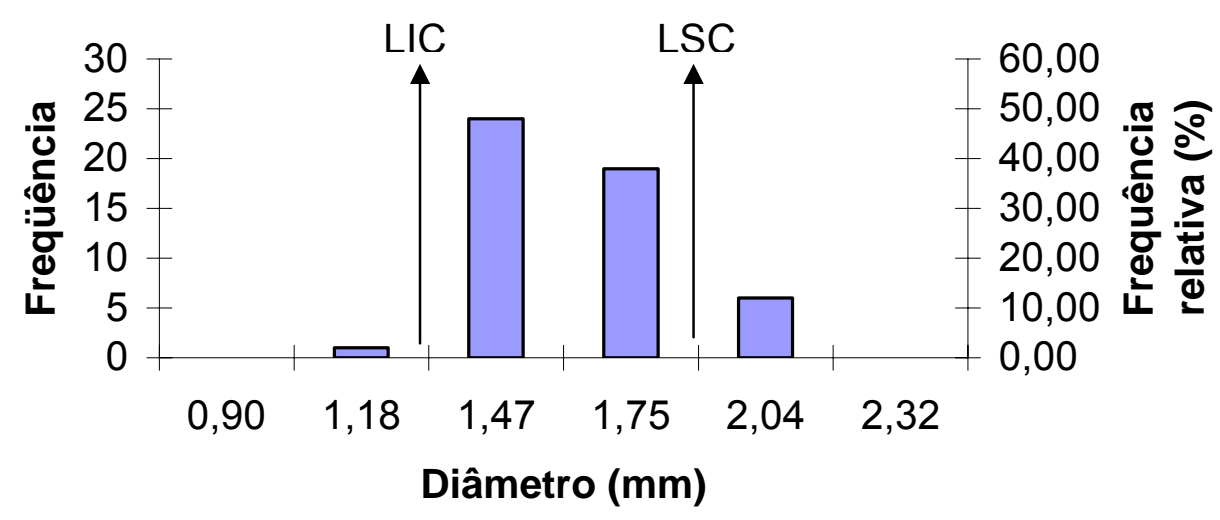

Figura 18 - Histograma do diâmetro do caule das plantas

\subsection{Diagrama de causa e efeito na produção de mudas de café}

No sistema de produção de mudas de café enxertado, a qualidade da muda está intrinsecamente relacionado com vários fatores relacionados e determinados através do diagrama 6M (Figura 19). Analisou-se os fatores determinantes da má qualidade da mudas de café, compreendendo que o tamanho inadequado das mudas provenientes dos germinadores, deficiência dos funcionários, principalmente os responsáveis pela enxertia e repicagem, que são os itens que possuem maior desuniformidade. Quanto aos equipamentos, a mesa vibratória é determinante na diferença de substrato entre tubetes. As condições edafo-climáticas destacam-se a temperatura e a umidade relativa do ar que atua acentuadamente principalmente no estádio inicial das mudas. 


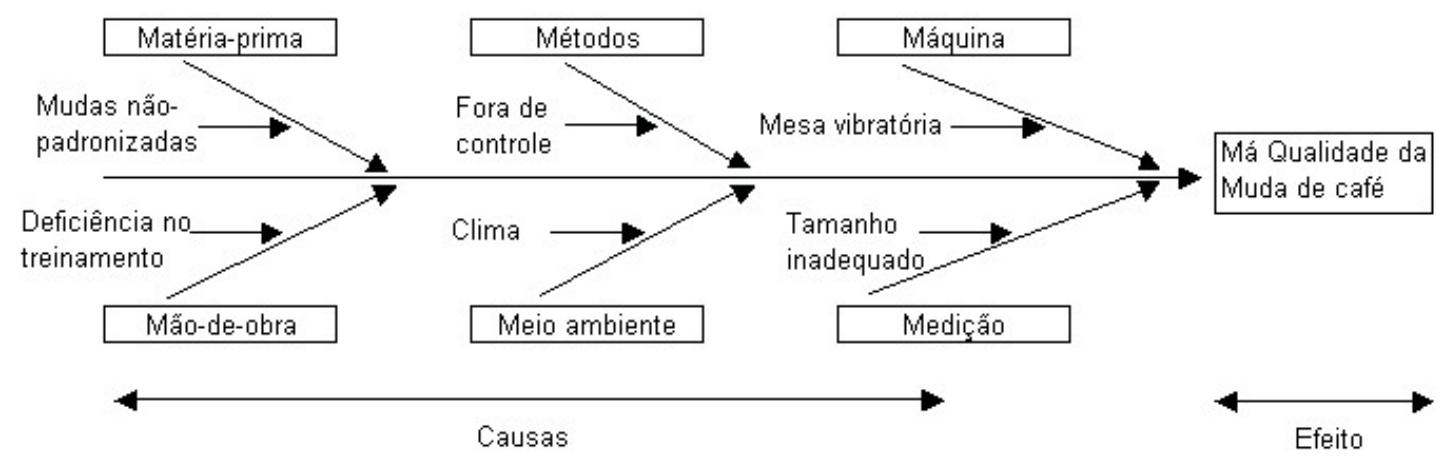

Figura 19 - Diagrama de Causa e Efeito na produção de mudas de café

\subsubsection{Profundidade de transplantio}

Dentre os problemas abordados no diagrama de causa e efeito, a profundidade de transplantio se destaca no processo de repicagem das mudas de café, principalmente por se tratar de um trabalho exclusivamente dependente da mão-de-obra. O gráfico de controle (Figura 20) apresentou seus valores fora dos limites de controle, com média de $30,9 \mathrm{~mm}$ e a amplitude varia entre 33,9 e $28,9 \mathrm{~mm}$, se aproximando em alguns casos dos limites inferiores e superiores de controle.

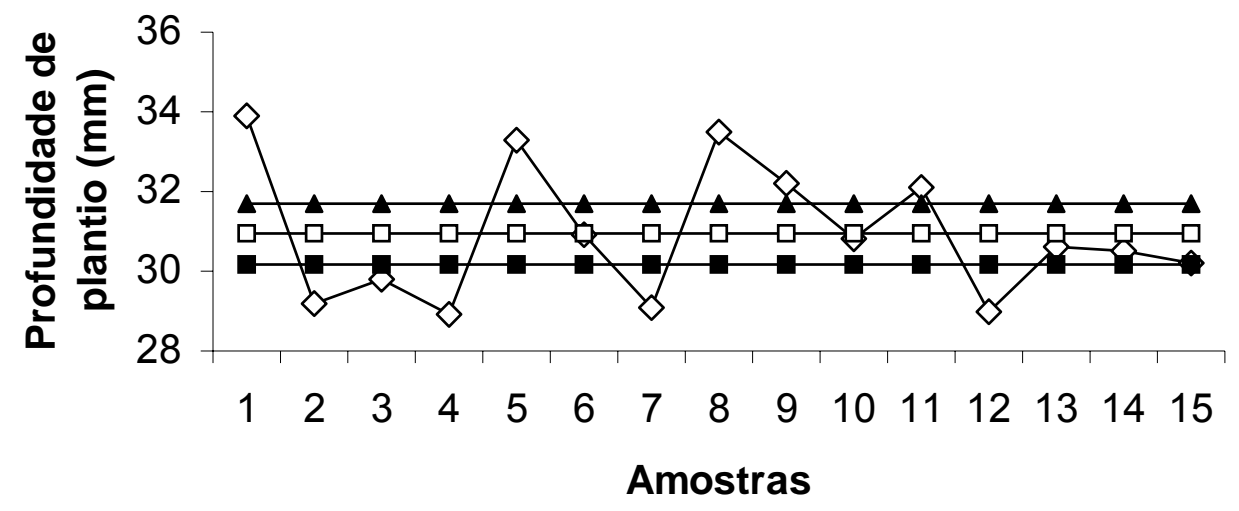

$\prec$ Amostras $\rightarrow-\mathrm{LM} \multimap \mathrm{LSC} \rightarrow-\mathrm{LIC}$

Figura 20 - Gráfico de controle para profundidade de transplantio (repicagem) 


\subsubsection{Altura da enxertia}

O item altura de enxertia também é diagnosticado como característica intrínseca ao desenvolvimento das mudas, principalmente quanto ao diagnóstico da altura final da muda de café. A altura da incisão varia de 32,1 a $42,1 \mathrm{~mm}$, com média de $36,5 \mathrm{~mm}$, mantendo-se fora de controle nas amostras observadas (Figura 21).

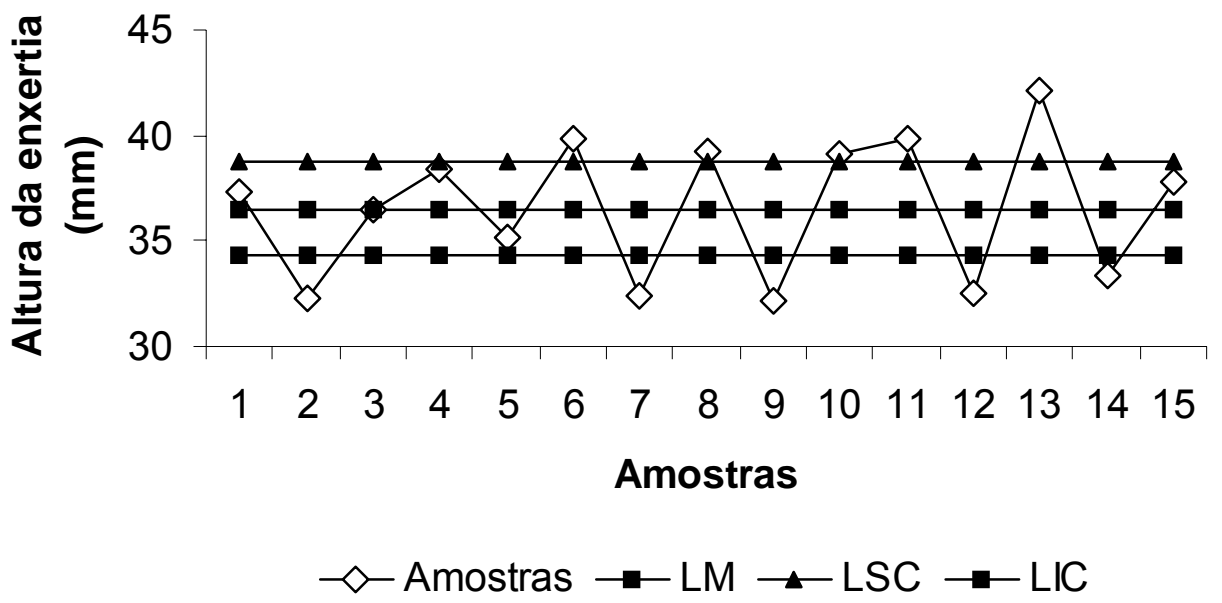

Figura 21 - Gráfico de controle para altura da enxertia

\subsubsection{Peso de substrato por recipiente}

O peso do substrato adicionado a cada tubete no sistema de enchimento através da mesa de vibração apresentou intervalos dentro e fora de controle, com média de 11,35 g/tubete com abruptos acréscimos $(13,86 \mathrm{~g} /$ tubete $)$ e decréscimos $(9,42 \mathrm{~g} /$ tubete $)$. As amostras de 1 a 6 apresentou amostras dentro dos limites inferiores e superiores de controle (Figura 22). Isso se deve principalmente ao acúmulo de substratos na parte central da bandeja, e déficit nos recipientes laterais associado à falta de capacitação da mão-de-obra. 


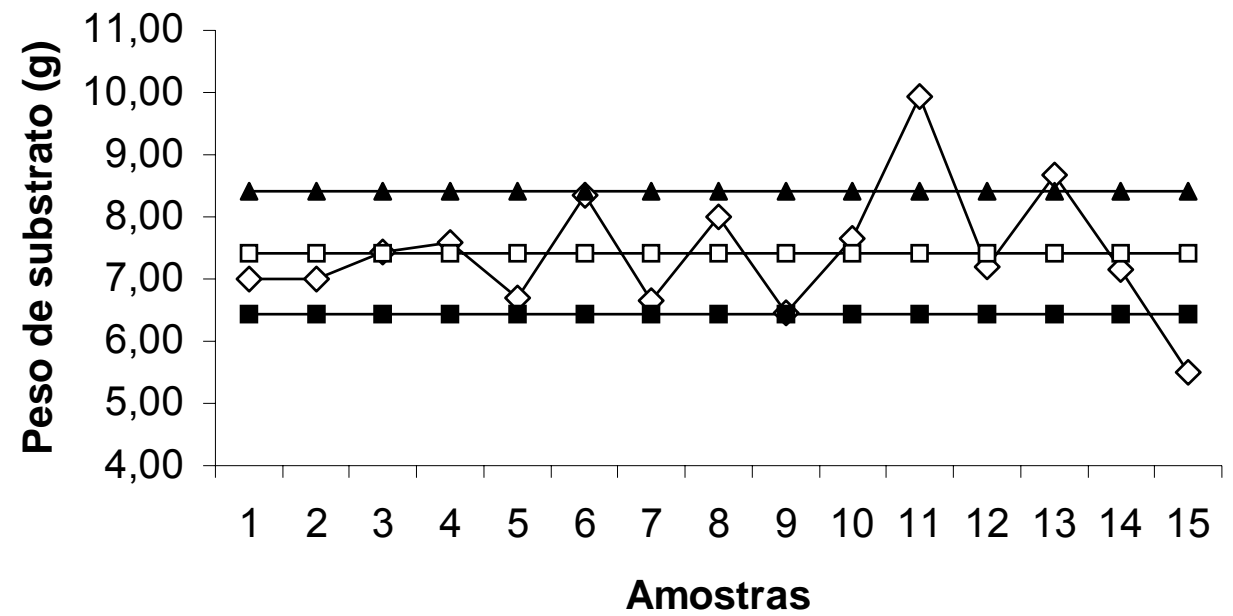

$\diamond$ Amostras $\square-\mathrm{LM} \rightarrow \mathrm{LSC} \rightarrow-\mathrm{LIC}$

Figura 22 - Gráfico de controle para peso de substrato (g) por tubete 


\section{CONCLUSÕES}

Através da análise dos resultados do trabalho concluiu-se que:

- As qualidades exigidas prioritárias para as da muda de café foram: prazo de entrega, enxerto bem-feito, preço acessível e condições de pagamento com pesos relativos de $7,8 \%, 6,1 \%, 5,2 \%$ e $5,2 \%$, respectivamente.

- As características da qualidade que apresentaram melhor classificação foram: o estado nutricional, massa seca da parte aérea, massa seca das raízes altura da planta e diâmetro do caule, com 13,0\%, 12,2\%, 10,8\%, 5,2\% e 5,2\%, respectivamente.

- A baixa classificação dos itens de características de qualidade correspondentes aos itens de qualidade exigida de maior peso relativo se sucedeu devido à baixa correlação na matriz de qualidade.

- As características obtidas através da matriz da qualidade e analisada através de ferramentas da qualidade apresentaram processos dentro dos limites de controle especificados.

- Os itens profundidade de plantio, altura de enxertia e peso de substrato por recipiente obtidos através do diagrama de causa e efeito se encontraram fora de controle no processo produtivo. 
ANEXOS 
ANEXO A- ENTREVISTA APLICADA AOS CLIENTES DE MUDAS DE CAFÉ

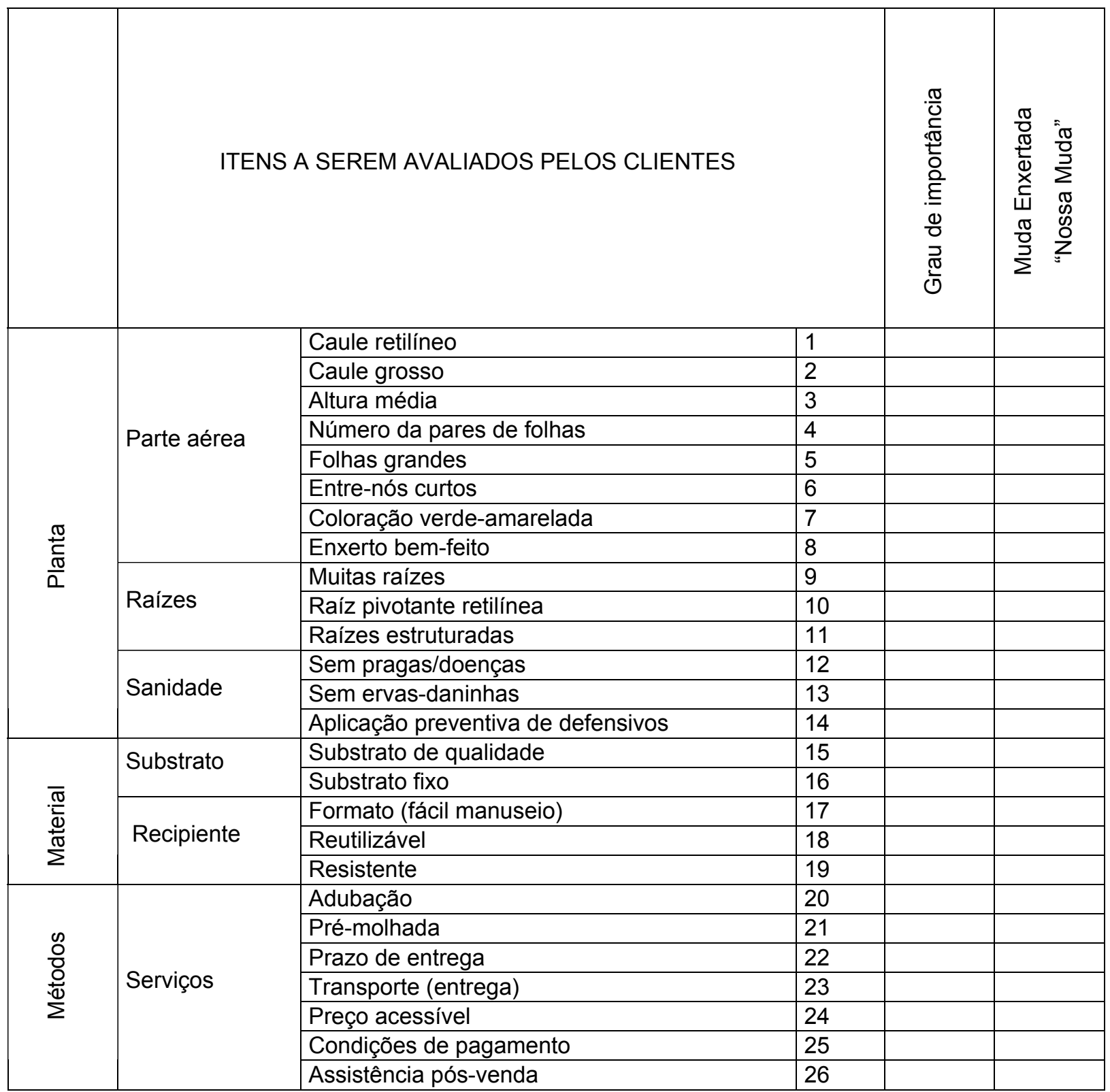


ANEXO B- RESULTADO DAS ENTREVISTAS APLICADO AOS CLIENTES DE MUDAS

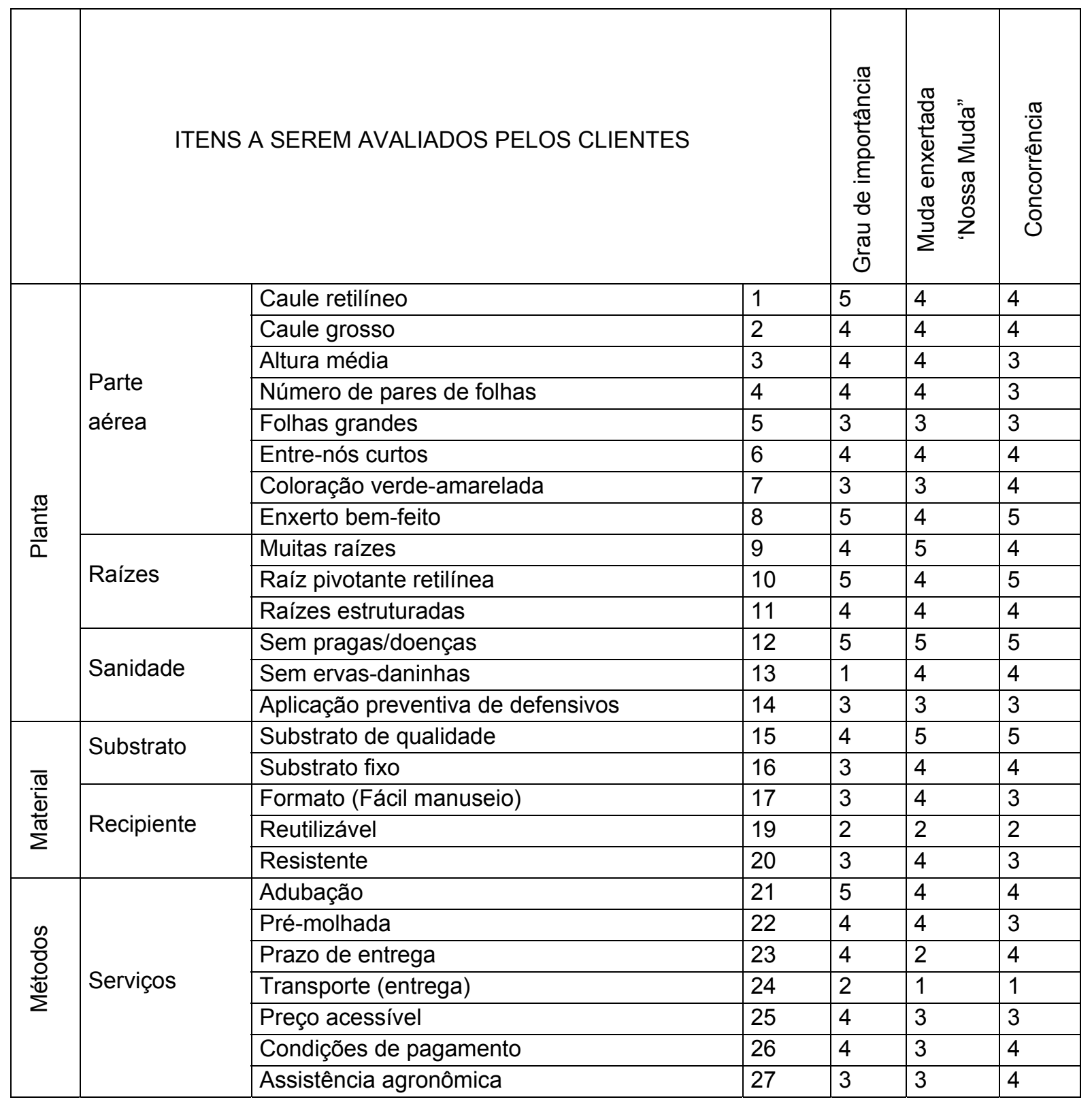




\section{REFERÊNCIAS BIBLIOGRÁFICAS}

ABIC, ASSOCIAÇÃO BRASILEIRA DA INDÚSTRIA DE CAFÉ, Estatísticas, 2004, www.abic.com.br

AKAO, Y. Introdução ao Desdobramento da Qualidade. Trad. de Z. T. Fujikawa e S. Takahashi, Belo Horizonte, MG: Fundação Christiano Ottoni, 1996. 187p.

BARBIZAN, E. L.; LANA, R. M. Q.; MENDONÇA, F. C.; MELO, B. DE; SANTOS, C. M. DOS; MENDES, A. F. Ciência Agrotécnica, Lavras. Ed. esp., p.14711480, dez., 2002

BARROS, J. W. D. Planejamento da qualidade do preparo mecanizado do solo para implantação de florestas de Eucalyptus spp utilizando o método desdobramento da função qualidade (QFD). Piracicaba, 2001. 117p. Dissertação (Mestrado) Escola Superior de Agricultura "Luiz de Queiroz", Universidade de São Paulo.

BARROSO, D.G.; CARNEIRO, J.G.A.; LELES, P.S.S.; MORGADO, I.F. Regeneração de raízes de eucalipto em recipientes e substratos. Scientia Agrícola, Piracicaba, v.57, n.2, p.229-237, abr/jun 2000.

BONILLA, J. A. Resposta à crise: Qualidade total e autêntica para bens e serviços, São Paulo: Makron Books, 1993. 238p. 
BONILLA, J. A. Qualidade total na agricultura: fundamentos e aplicações. Belo Horizonte: Centro de estudos de qualidade total na agricultura, 1994. 344p.

CAMPOS, V. F. TQC Controle de qualidade total (no estilo japonês). Belo Horizonte: Editora de Desenvolvimento Gerencial, 1992. 230p.

CAMPOS, K.P. Produção de mudas de cafeeiro (Coffea arabica L.) em diferentes espaçamentos, substratos, adubações e tamanhos de tubetes. Lavras, 2002. 90p. Dissertação (Mestrado) - Universidade Federal de Lavras.

CARNEIRO, J. G. de A. Produção e controle de qualidade de mudas florestais. Curitiba: UFPR/FUPEF, 1995. 451p.

CARNEVALLI, J. A.; SASSI, A.C.; MIGUEL, P. A. C. Aplicação do QFD no desenvolvimento de produtos: levantamento sobre seu uso e perspectivas para pesquisas futuras. Gestão e Produção, v.11, n.1, p.33-49, jan./abr, 2004.

CHENG, L. C., SCAPIN, C. A., OLIVEIRA, C. A. De, KRAFETUSKI, E., DRUMOND, F.B., BOAN, F. S., PRATES, L. R., VILELA, R. M. QFD: Planejamento da Qualidade, Belo Horizonte: UFMG; Fundação Christiano Ottoni, 1995, 262p.

CONAB. COMPANHIA NACIONAL DE ABASTECIMENTO. http://www.conab.gov.br/ ( 02 mar. 2004).

DELLARETTI FILHO, O. As sete ferramentas do planejamento da qualidade, Belo Horizonte: UFMG, Fundação Christiano Ottoni, 1996. 183p.

DELLARETTI FILHO, O.; DRUMMOND, F.B. Itens de controle e avaliação de processos. Belo Horizonte: Fundação Christiano Ottoni, 1994., 151p. 
FAVARIN, J.L. Características da semente em relação ao seu potencial fisiológico e a qualidade de mudas de café (Coffea arabica L.). Revista Brasileira de Sementes, v.25, n.2, p.13-19, 2003.

FESSEL, Qualidade, desempenho operacional e custos de plantios, manual e mecanizado, de Eucalyptus grandis, implantados com cultivo mínimo do solo. Piracicaba, 2003. 88p. Dissertação (Mestrado) - Escola Superior de Agricultura “Luiz de Queiroz”, Universidade de São Paulo.

FELÍCIO, P.E. de. Higiene Alimentar, São Paulo, v.12, n.54, p.16-22, 1998.

GAITHER, N., FRAZIER, G. Administração da produção e operações, Trad. de J. C. B. dos Santos. 8.ed. São Paulo: Pioneira, 2001. 598p

GUINTA, L.R.; PRAIZLER, N.C. Manual de QFD. Trad. de R. Raposo, Rio de Janeiro: LTC, 1993. 140p.

GALUCH, L. Modelo para implementação das ferramentas básicas do controle estatístico de processo - CEP em pequenas empresas manufatureiras. Florianópolis, 2002. 86p. Dissertação (Mestrado) - Universidade Federal de Santa Catarina.

GOMES, J.M. et al. Efeito de diferentes substratos na produção de mudas de Eucalyptus grandis W. Hill ex Maiden em “Win Strip”. Revista Árvore, v.15, n.1, 35-42 p., 1991

GOMES, J.M.; COUTO, L.; LEITE, H.G.; XAVIER, A.; GARCIA, S.L.R. Parâmetros morfológicos na avaliação da qualidade da qualidade de mudas de Eucalyptus grandis. Revista Árvore, v.26, n.6, p.655-664, 2002. 
GOVERS, C.P.M.; What and how about quality function deployment (QFD). International jornal of production economics. v.46/47, p.575-585, 1996

GUAZZI, D. M. Utilização do QFD como ferramenta de melhoria contínua do grau de satisfação de clientes internos: Uma aplicação em cooperativas agropecuárias. Florianópolis, 1999. 209p. Tese (D.S.) - Universidade Federal de Santa Catarina.

GUIMARÃES, P. T. G.; ANDRADE NETO, A; BELLINI JUNIOR, O.; ADÃO, W.A.; SILVA, E. M. da; A produção de mudas de cafeeiro em tubetes, Informe Agropecuário, Belo Horizonte, v.19, n. 193, p.98-109, 1998.

HAKES, CHRIS, Total quality management: The key to business improvement, New York: 1991. 182p.

IBGE, INSTITUTO BRASILEIRO DE GEOGRAFIA E ESTATÍSTICA, Levantamento sistemático da produção agrícola, 2004, www.ibge.gov.br

MARCOS, S. K. Desenvolvimento de tomate de mesa, com o uso do método QFD (Quality Function Deployment), comercializado em um supermercado. Campinas, 2001. 200p. Tese (D.S.) - Universidade Estadual de Campinas.

MATIELLO, J. B. O café: do cultivo ao consumo. São Paulo: Globo, 1991. 320p. (Coleção do Agricultor.)

MELO, B. Estudos sobre a produção de mudas de cafeeiro (coffea arabica L.) em tubetes, Lavras, 1999. 119p.Tese (Doutorado) - Universidade Federal de Lavras 
MIGUEL, P. C., WEIDMANN, A. Construção da casa da qualidade: exemplo didático para o ensino do desdobramento da função qualidade (QFD). Revista de Ensino de Engenharia, v.18, n.1, p.41-50, 1999.

MIGUEL, P. A. C.; TElFSER, M.; MARUCA, A.; GALLONETTI, A.; SARACURA, A., MARTINS, L.; HORI, M., RIBEIRO, P.; CAMPOS, R. DE; MARCONATO, T.; MORA, V. Desdobramento da qualidade no desenvolvimento de filmes flexíveis para embalagens. Polímeros, v.13, n.2, p.87-94. abr./jun. 2003.

MILAN, M., BARROS, J. W. D., GAVA, J. L. Planning soil tillage using quality function deployment (QFD). Scientia Agrícola, v.60, n.2, p.217-221, abr/jun.2003.

MILAN, M; FERNANDES, R.A.T. Qualidade das operações de preparo de solo por controle estatístico de processo. Scientia Agrícola, v.59, n.2, p.261-266, abr/jun. 2003

MINAMI, K. Produção de mudas de alta qualidade em horticultura. São Paulo: T. A. Queiroz, 1995. 128p

MIRSHAWKA, V.; MIRSHAWKA JR. QFD, A vez do Brasil: Saiba o que se quer e o que ocorre. São Paulo: Makron Books, 1994. 189p.

MONTGOMERY, D. C. Introduction to statistical quality control. New York: John Wiley, 1997.677p.

PASQUA, Controle de qualidade em operações agrícolas mecanizadas na cultura do milho (Zea mays I.). In: CONGRESSO BRASILEIRO DE ENGENHARIA AGRÍCOLA, 25:; CONGRESSO LATINO AMERICANO DE INGENERIA AGRICOLA, 2., Bauru, 1996. Resumos, Unesp/SBEA/Alia, 1996. 89p. 
PECHE FILHO, A; SILVA, L. C. da; BÊN, J. C.; NAGAOKA, A. K. Avaliação da qualidade de subsolagem com base em medidas de profundidade na reformulação de lavoura de cana-de-açúcar. In: CONGRESSO BRASILEIRO DE ENGENHARIA AGRÍCOLA, 31., Salvador, 2002, Resumos. Salvador: 2002. $73 p$.

SARRIÉS, G.A. Controle estatístico da qualidade para impurezas minerais em carregamentos de cana-de-açúcar. Piracicaba, 1997. 88p. Tese (Doutorado) Centro de Energia Nuclear na Agricultura, Universidade de São Paulo.

SERA, T. Mudas de café. Endereço [ on-line ] Disponível: tsera@iapar.br, (16 jul. 2004).

SILVA, L.S.C.V. DA. Aplicação do controle estatístico de processo na industria de laticínios lactoplasa: um estudo de caso. Santa Catarina, 1999. 97p. Dissertação (Mestrado) - Universidade Federal de Santa Catarina.

SILVA, V. O. Perspectivas no mercado de café: perspectivas para o agribusiness em 2004 e 2005... São Paulo: BM\&F, 2004. 25p.

SIQUEIRA, L. G. P. Controle estatístico do processo, Equipe Grifo, São Paulo: Pioneira, Biblioteca Pioneira de Administração e Negócios, 1997. (Série qualidade Brasil), 129p.

STAHL, M.J., Management: Total quality in a global environment, University of Tenessee, Blackwell Business, 1995. 546p. 
SUGUISAWA, J.M. Diagnóstico da condição tecnológica, sob a ótica da qualidade, das operações mecanizadas da cultura do trigo em sistema plantio direto. Piracicaba, 2004. 110p. Dissertação (Mestrado) - Escola Superior de Agricultura "Luiz de Queiroz", Universidade de São Paulo.

TALMASKY, E.M. A gestão da qualidade no desenvolvimento de produtos moveleiros. In: CONGRESSO NACIONAL DE EXCELÊNCIA EM GESTÃO, Niterói, 2002. Resumos. Niterói: UFF, 2002. 82p.

TAVARES JÚNIOR, J. E. Volume e granulometria do substrato na formação de mudas de café. Piracicaba, 2004, 73p. Dissertação (Mestrado) - Escola Superior de Agricultura "Luiz de Queiroz", Universidade de São Paulo.

THOMAZIELLO, R. A. FAZUOLI, L. C., PEZZOPANE, J. R. M., FAHL, J. I., CARELLI, M. L. C. Café arábica: cultura e técnicas de produção., Campinas: Instituto Agronômico, 2000. 82p. (Boletim técnico 187).

TRINDADE, C. Desenvolvimento de um sistema de controle de qualidade para a atividade florestal. Viçosa, 1993. 164p. Dissertação (Mestrado) - Universidade Federal de Viçosa

TRINDADE, C.; REZENDE, J.L.P.; JACOVINE, L.A.C.; SARTORIO, M.L. Ferramentas da qualidade. Viçosa, Editora UFV, 2000. 124p. 